\title{
Design of a new multi-phase experimental simulation chamber for atmospheric photosmog, aerosol and cloud chemistry research
}

\author{
J. Wang, J. F. Doussin, S. Perrier, E. Perraudin, Y. Katrib, E. Pangui, and B. Picquet-Varrault \\ LISA, Universités Paris-Est-Créteil et Paris Diderot, CNRS UMR7583, 61 Av. du Général de Gaulle, 94010 Créteil, France \\ Received: 27 November 2010 - Published in Atmos. Meas. Tech. Discuss.: 18 January 2011 \\ Revised: 3 July 2011 - Accepted: 20 October 2011 - Published: 24 November 2011
}

\begin{abstract}
A new simulation chamber has been built at the Interuniversitary Laboratory of Atmospheric Systems (LISA). The CESAM chamber (French acronym for Experimental Multiphasic Atmospheric Simulation Chamber) is designed to allow research in multiphase atmospheric (photo-) chemistry which involves both gas phase and condensed phase processes including aerosol and cloud chemistry. CESAM has the potential to carry out variable temperature and pressure experiments under a very realistic artificial solar irradiation. It consists of a $4.2 \mathrm{~m}^{3}$ stainless steel vessel equipped with three high pressure xenon arc lamps which provides a controlled and steady environment. Initial characterization results, all carried out at 290-297 K under dry conditions, concerning lighting homogeneity, mixing efficiency, ozone lifetime, radical sources, $\mathrm{NO}_{\mathrm{y}}$ wall reactivity, particle loss rates, background PM, aerosol formation and cloud generation are given. Photolysis frequencies of $\mathrm{NO}_{2}$ and $\mathrm{O}_{3}$ related to chamber radiation system were found equal to $\left(4.2 \times 10^{-3} \mathrm{~s}^{-1}\right)$ for $J_{\mathrm{NO}_{2}}$ and $\left(1.4 \times 10^{-5} \mathrm{~s}^{-1}\right)$ for $J_{\mathrm{O}^{1} \mathrm{D}}$ which is comparable to the solar radiation in the boundary layer. An auxiliary mechanism describing $\mathrm{NO}_{\mathrm{y}}$ wall reactions has been developed. Its inclusion in the Master Chemical Mechanism allowed us to adequately model the results of experiments on the photo-oxidation of propene- $\mathrm{NO}_{\mathrm{x}}-\mathrm{Air}$ mixtures. Aerosol yields for the $\alpha$-pinene $+\mathrm{O}_{3}$ system chosen as a reference were determined and found in good agreement with previous studies. Particle lifetime in the chamber ranges from $10 \mathrm{~h}$ to 4 days depending on particle size distribution which indicates that the chamber can provide high
\end{abstract}

Correspondence to: J. F. Doussin (jean-francois.doussin@lisa.u-pec.fr) quality data on aerosol aging processes and their effects. Being evacuable, it is possible to generate in this new chamber clouds by fast expansion or saturation with or without the presence of pre-existing particles, which will provide a multiphase environment for aerosol-droplet interaction.

\section{Introduction}

It is well known that the emission of pollutants such as nitrogen oxides, volatile organic compounds (VOC), and particulate matter into the troposphere may present a health risk either directly, or as a result of their transformation. Indeed, gaseous species lead to a variety of secondary oxidized products, many of them being often more harmful than their precursors. These photochemical oxidants which include ozone, peroxyacyl nitrates, nitric acid are of particular concern, since there are known to have adverse effects on human health, vegetation and even climate (Marenco et al., 1994; Seinfeld and Pandis, 1997; Finlayson-Pitts and Pitts Jr., 2000; IPCC, 2007).

Furthermore, atmospheric organic matter undergoes progressive oxidation during its chemical transformations, to yield products, generally oxygenated, that have sufficiently low vapor pressures to partition themselves between gas and aerosol phases (Seinfeld and Pankow, 2003; Kanakidou et al., 2005). These phase change processes affect the atmospheric aerosol either by leading to the formation of new particles (nucleation) or by participating in the chemical aging of pre-existing particles (condensation). Moreover, chemical transformations can also occur in the condensed phase. All these processes are susceptible to modify the physicochemical properties of atmospheric aerosols. 
Since, in the ambient, it is difficult to separate the chemistry from meteorology and other processes, closed systems have been developed since the late 1960s (Becker, 2006). While not totally artifact-free, these simulation chambers (or "smog chambers") provide a controlled environment to study the formation and the evolution of atmospheric pollutants, by isolating specific compounds of interest and controlling the oxidizing environment.

Initially, smog chamber experiments were essentially focused on the understanding of atmospheric oxidation mechanisms in the gas phase. This approach has been extremely useful to produce kinetic data, branching ratio and product distributions (Becker, 2006). Together with data arising from flow tubes or flash photolysis experiments, this knowledge allowed the scientific community to build complex numerical codes that led to the development of the models used to predict ozone formation. Nowadays, chambers are also essential tools for evaluating these chemistry modules and for predicting the formation of secondary pollutants in the absence of uncertainties associated with emissions, meteorology, and mixing effects (Carter and Lurmann, 1991; Dodge, 2000; Hynes et al., 2005).

In the past few decades, these installations have been used to investigate processes leading to secondary pollutants formation such as ozone and secondary organic aerosols (SOA) (Finlayson-Pitts and Pitts Jr., 1986, 2000; Dodge, 2000; Kanakidou et al., 2005; Barnes and Rudzinski, 2006; Hallquist et al., 2009). The methodology which has been (and still is) useful for gaseous pollutants is now providing data concerning SOA formation (Hatakeyama et al., 1991; Pankow, 1994; Odum et al., 1996; Cocker III et al., 2001a, b; Pun et al., 2003; Takekawa et al., 2003; Wirtz and MartinReviejo, 2003; Baltensperger et al., 2005; Donahue et al., 2005; Zhang et al., 2006; Pathak et al., 2007) as well as concerning the physico-chemical properties of aerosols and their changes during the atmospheric transport (De Haan et al., 1999; Kalberer et al., 2006; Field et al., 2006; Linke et al., 2006; Camredon et al., 2007; Meyer et al., 2009).

Aside small Teflon ${ }^{\circledR}$ bags of few hundred liters, less than 30 chambers are currently in operation around the world (16 in Europe coordinated in the framework of the European Environmental Chamber Network - EuroChamp http://www.eurochamp.org). Furthermore, due to the number of combinations in design criteria, these reactors appear to be more complementary than redundant. As pointed out by Finlayson-Pitts and Pitts Jr. (2000), although the general aims of all chamber studies are similar - i.e. to simulate reactions in ambient air under controlled conditions - the chamber designs and capabilities to meet these goals vary widely.

In particular, simulation chambers are not without any limitations or possible artifacts. For example, as the principle of the experimental simulation is to enclose a parcel of air, the reactor walls are unavoidable elements where reactions can occur and affect the realism of the simulation. Simi- larly, the chamber approach implies inherently to study simplified atmospheres at low concentrations. In consequence, background chemicals, off-gassing materials and memory effects may complicate the chemical composition of the studied mixture and hence the reliability of the data (Carter and Lurmann, 1991; Dodge 2000). The irradiation energy and its spectral distribution is also a potential problem when the light source is artificial or when the walls are partly opaque by promoting non-realistic reactions or inhibiting reactions of atmospheric relevance (Winer et al., 1979).

The mitigation of these potential problems is one of the main goals when designing an atmospheric simulation chamber. The main characteristics which define the various chambers can be summarized as the diverse answers to the following questions: (1) what is its size? (2) how is it irradiated? (3) what is the reactor made of? (4) to which extent can the temperature be modified? (5) to which extent can the pressure be modified?

Size is probably among the most critical parameters. Indeed, for comparable shapes, the bigger the reactor, the smaller the surface-to-volume ratio $(S / V)$, and thus the less important unwanted surface reactions will be. Nevertheless, Finlayson-Pitts and Pitts Jr. (2000) in the "Environmental chamber" section of their comprehensive textbook have pointed out that surface reactions are also significantly occurring in the lower part of the atmosphere and that wall reactions must also be taken into account when extrapolating chamber results to atmospheric conditions. On the other hand, large $S / V$ also helps in minimizing aerosol wall deposition. Large volume is also required to ease the preparation of very low concentration mixtures and to facilitate the use of analytical instruments developed for field measurements which commonly exhibit sampling rates in the range of liters per minute.

For technical and economical reasons, size is often strongly correlated with the material used. Except for the AIDA chamber (Bunz et al., 1996), most of the chambers bigger than few tenth cubic-meters are made of Teflon ${ }^{\circledR}$ film (Cocker et al., 2001a; Jaoui et al., 2004; Carter et al., 2005; King et al., 2010). In this case, most of these chambers are installed outdoors (Leone et al., 1985; Liu et al., 1999; Brauers et al., 2003; Karl et al., 2004; Martin-Reviejo and Wirtz, 2005) and benefit from solar light. However, these chambers are necessarily operated at atmospheric pressure.

On the contrary, smaller smog chambers are often indoor. They can be made of Teflon ${ }^{\circledR}$ film (Mentel et al., 1996; Thuener et al., 2004; Carter et al., 2005; Paulsen et al., 2005; King et al., 2010), Pyrex ${ }^{\circledR}$ (Barnes et al., 1979; Behnke et al., 1988; Hjorth et al., 1987; Doussin et al., 1997), quartz (Barnes et al., 1987), aluminum (Akimoto et al., 1979a; Winer et al., 1980) or stainless steel (De Haan et al., 1999; Glowacki et al., 2007). These indoor chambers are generally equipped with irradiation systems which comprise combination of black fluorescent lamps (Becker, 1996; Doussin et al., 
1997; Cocker et al., 2001), "sun" lamps (Doussin et al., 1997; De Haan et al., 1999), or/and xenon arc lamps (Winer et al., 1980; Carter et al., 2005). Depending on the transparency properties of the building material of the chamber, the irradiation can be more or less homogeneous and the transmitted spectrum inside the chamber more or less comparable with the solar spectrum.

As simulation chambers are enclosed volumes in which energy is injected through lighting, temperature control is often critical to prevent any overheating affecting the realism of the simulation. Furthermore, as temperatures in the troposphere range from roughly $+40^{\circ} \mathrm{C}$ to $-60^{\circ} \mathrm{C}$, kinetic parameters and phase change partitioning should be determined over this range. Indeed, several authors have pointed out the lack of information on temperature dependence of atmospheric processes used for model parameterization (Hatakeyama et al., 1991; Atkinson, 2000; Takekawa et al., 2003; Donahue et al., 2005; Atkinson et al., 2006, 2007; Saathoff et al., 2009). Depending on the material used for chambers, temperature control is often difficult to achieve. For indoor Teflon ${ }^{\circledR}$ film chambers, temperature control is sometimes achieved by using air conditioning of the room (Takekawa et al., 2003; Carter et al., 2005; Paulsen et al., 2005) while for rigid chambers, a cooling liquid is allowed to circulate around the reactor (Akimoto et al., 1979a; Barnes et al., 1979; De Haan et al., 1999; Glowacki et al., 2007; Saathoff et al., 2009). In this latter design, the temperature range available is often larger allowing these chambers to be baked in order to facilitate low vapor pressure compounds desorption during cleaning (Akimoto et al., 1979a; De Haan et al., 1999) or to study low temperature processes (Field et al., 2006; Saathoff et al., 2009; Behnke et al., 1988). For outdoor chambers, temperature control is more difficult to achieve and the device in use can be better described as limiting temperature changes during an experiment than controlling temperature (Martin-Reviejo and Wirtz, 2005).

The above section demonstrates the variety of possible characteristic combinations and how it may affect the field of operability of the chambers. For a more comprehensive review of the chambers in use in the atmospheric chemistry community, one may refer to Becker (2006), Seakins (2010) or to Finlayson-Pitts and Pitts Jr. (2000). In addition, an exhaustive description of the chambers in use in Europe can be found within the Eurochamp consortium (http://www. eurochamp.org).

This paper describes the design and the testing of a novel indoor chamber (CESAM : French acronym for Experimental Multiphasic Atmospheric Simulation Chamber Chambre Expérimentale de Simulation Atmosphérique Multiphasique) recently constructed at the Interuniversitary Laboratory of Atmospheric Systems (LISA). CESAM is a large stainless steel facility designed to allow research in multiphase atmospheric (photo)-chemistry which involves both gas phase and condensed phases processes including aerosol and cloud chemistry. It has the potential to carry out variable temperature and pressure experiments under a very realistic artificial solar irradiation, while allowing long lifetime to particles and permitting the generation of artificial clouds. Aside the study of the physico-chemical behavior of atmospheric pollutants, CESAM can also be used as a test platform for field instrument development or calibration.

\section{Facility description}

\subsection{Reactor chamber design}

The indoor CESAM chamber is a closed cylindrical vessel of internal dimensions of $1.7 \mathrm{~m}$ diameter and $2.3 \mathrm{~m}$ height. The reactor volume is of $4.2 \mathrm{~m}^{3}$ and the ratio of interior surface to volume is about $4.3 \mathrm{~m}^{-1}$. This rigid reactor is made of 3041 stainless steel and is vacuum compatible. It can be operated over a range of pressure from $10^{-7}$ to $2 \mathrm{~atm}$. Indeed the body of the chamber comprises four main parts leak-free tightened together thanks to $1750 \times 15 \mathrm{~mm}$ Viton ${ }^{\circledR}$ O-ring. The four parts consist of two intermediate stages; one elliptical bottom and one elliptical top (see Fig. 1). The chamber body is mounted on a cement framework with help of six adjustable anti-vibrating stands in order to limit the vibration effects coming from the ground level and the pumping system. The chamber is connected to the ground to prevent any electrical charge build-up. The intermediate stages comprise, in total, 8 medium size DN350LF ports of $0.35 \mathrm{~m}$ diameter and 4 larger DN450LF ports of $0.45 \mathrm{~m}$ diameter on which the input and sampling lines, as well the analytical instruments are installed while the top part carries the irradiation ports.

The reactor body is made of double layers which allow circulating a warm or cold fluid around in order to control the reactor temperature. The inner walls which support most of the mechanical constraints when the reactor is under vacuum have a thickness of $12 \mathrm{~mm}$ while the outer wall thickness is of $2 \mathrm{~mm}$. A $10 \mathrm{~mm}$ space between the two walls has been kept forming a volume of 901 for the thermal fluid circulation. The inner wall is polished to minimize the specific surface area and to provide a good light reflection inside the chamber for being able to enhance the radiation lighting homogeneity. For reactant injection and sampling, gas and aerosol inlets and outlets are either made of PTFE or stainless steel. One special inlet line mounted near the mixing fan installed at the bottom level of the reactor is used for fast gas injection.

\subsection{Pumping device}

The chamber vacuum system consists of two pumps for both gas and aerosol evacuation: a screw vacuum pump (Bush ${ }^{\circledR}$ Cobra $^{\mathrm{TM}}$ N0100-0300B) provides a maximum primary vacuum of $10^{-2} \mathrm{mbar}$, at a pumping speed of about $1101 \mathrm{~s}^{-1}$ at 500 mbar. This dry pump is oil-free which allows us to work with very clean residual atmosphere under vacuum and 


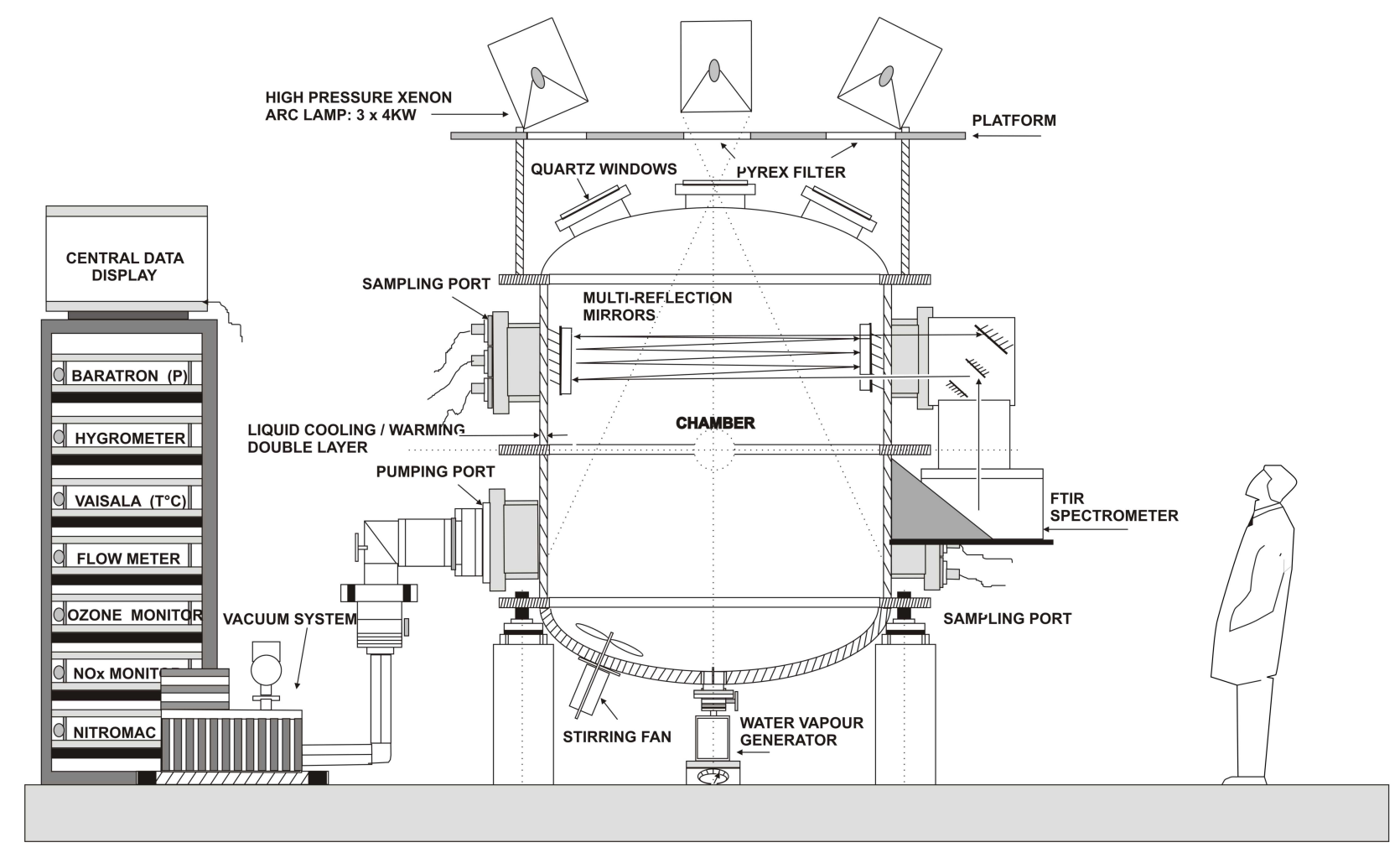

Fig. 1. Schematic front view of the CESAM facility.

prevents any low vapor pressure hydrocarbons originating from the pump from affecting the particle production. Furthermore, this pump is designed to allow without damage the evacuation of aerosols (including those made of abrasive particles) which is of great interest for future studies involving mineral dust. The speed of the primary pump is further enhanced by a root pump (Leybold ${ }^{\circledR}$ RUVAC $^{\mathrm{TM}}$ WAU 501) on its forehead. The coupling of these two pumps gives access to a nominal pumping speed of $160 \mathrm{~m}^{3} \mathrm{~h}^{-1}$ and allows reaching the secondary vacuum threshold (i.e. 0.05 mbar) in ca. $30 \mathrm{~min}$. The secondary vacuum is reached thanks to a turbo pump (Leybold ${ }^{\circledR}$ Turbovac $361^{\circledR}$ ). The vacuum limit for CESAM falls in the range of $10^{-4}$ mbar (see below) and depends on the walls cleanliness, the reactor seal conditions and, in particular, on the vacuum compatibility of the various inlets and connections attached to the flanges.

\subsection{Mixing}

A 4-wing stainless steel fan of $50 \mathrm{~cm}$ diameter is installed inside the reactor, at the bottom of the chamber. It is used to mix gas compounds and particles throughout the whole chamber volume. The fan is equipped with a high-vacuum magnetic feed-through allowing the installation of an electric motor outside the chamber (UHV Design Ltd./MagiDrive ${ }^{\mathrm{TM}}$ MD35) for preventing any contamination from mechanical oil or grease. The fan speed can be varied as a function of the input power supply, the maximum operational rate being ca. $300 \mathrm{rpm}$.

\subsection{Irradiation}

Three $4 \mathrm{~kW}$ high-pressure arc xenon lamps (MHDiffusion ${ }^{\circledR}$, MacBeam ${ }^{\mathrm{TM}}$ 4000) are located symmetrically above the chamber on one large movable and rigid framework. There are used to irradiate the reaction volume by passing through three quartz windows of $25 \mathrm{~cm}$ diameter and $4 \mathrm{~cm}$ thickness. This material is transparent to photons from $200 \mathrm{~nm}$ on. By optimizing the focal point of the light beam, one can obtain a converging or diverging light beam with a maximum intensity inside the reactor; meanwhile the light spots projected at bottom level of the chamber are as large as possible to minimize local overheating effects. This feature can be used to increase or reduce light intensity in the chamber reactor by adjusting the solid angles of the light beams. In addition the lamps can be operated at full power $(4 \mathrm{~kW})$ for a maximum light intensity but also at 1,2 or $3 \mathrm{~kW}$ if needed.

\section{Basic analytical equipment}

The CESAM chamber is equipped with a large panel of analytical instruments dedicated to gas and particulate measurements as well as instruments for monitoring the physical 
parameters of the chamber. This default set of apparatus defines an ensemble presented in Table 1. However, a number of available ports provide space for the connection of other instruments which can be temporarily required to address specific scientific issues.

\subsection{Physical parameters}

\subsubsection{Pressure}

A set of pressure gauges is used to monitor the absolute pressure in the chamber. Two capacitance manometers MKS ${ }^{\circledR}$ Baratrons ${ }^{\circledR}$ (MKS, 622A and MKS, 626A) are installed side by side with one IR090 Sky Hot Ion Combi Gauge Inficon ${ }^{\circledR}$ operated with a Combivac ${ }^{\circledR}$ IT23 from Leybold Company. This model of pressure gauge consists of two separate measuring systems: a Bayard-Alpert hot cathode and a Pirani thermal conductivity gauge coupled in a single system. The overall ensemble of manometers allows performing chamber pressure measurements from to $10^{-7}$ to $1500 \mathrm{mbar}$.

\subsubsection{Relative humidity and temperature}

Both temperature and relative humidity are measured thanks to a HMP234 Vaisala ${ }^{\circledR}$ humidity and temperature transmitter equipped with a capacitive thin-film polymer sensor Humicap ${ }^{\circledR}$. The gauge has been designed for measurements in pressurized spaces or vacuum chambers and can be operated at the absolute pressure as high as $10 \mathrm{~atm}$. The temperature measurement ranges from $-40^{\circ} \mathrm{C}$ to $180^{\circ} \mathrm{C}$ with an accuracy of $0.1{ }^{\circ} \mathrm{C}$ at $20^{\circ} \mathrm{C}$. The relative humidity can be measured from $0 \%$ to $100 \%$ with an accuracy higher than $3 \%$. While the manufacturer indicates that the response time of this sensor is equal to $15 \mathrm{~s}$, it has been observed that the measurements need at least 3 min to stabilize after a fast increase of the relative humidity in the chamber.

\subsection{Gaseous species measurements}

\subsubsection{In situ monitors}

For the measurement of most common gaseous species involved in photosmog chemistry (e.g. $\mathrm{O}_{3}, \mathrm{NO}_{\mathrm{x}}, \mathrm{SO}_{2}$ ), different ambient monitors are used.

For ozone measurement, an APOA-370 from Horiba ${ }^{\circledR}$ is permanently installed. The APOA-370 uses a cross flow modulation to measure $\mathrm{O}_{3}$ concentration in ambient air by ultraviolet absorption with a sampling rate of $11 \mathrm{~min}^{-1}$. The arrangement offers a response time of 75 seconds and a detection limit of $500 \mathrm{ppt}$.

For the measurement of nitrogen oxides ( $\mathrm{NO}$ and $\mathrm{NO}_{2}$ ), an APNA-370 from Horiba ${ }^{\circledR}$ is permanently installed. The APNA-370 continuously monitors $\mathrm{NO}_{2}$ and NO concentrations by using a cross-flow modulated semi-decompression chemiluminescent method. With a sampling rate of $11 \mathrm{~min}^{-1}$ this instrument reaches a detection limit of $500 \mathrm{ppt}$ with a response time of $90 \mathrm{~s}$. It has to be noted that when $\mathrm{NO}_{\mathrm{y}}$ concentrations are high compared to $\mathrm{NO}_{2}$ levels, these species may introduce a significant positive artifact which may reach $100 \%$ (Dunlea et al., 2007). Considering this characteristic of this type of analyzer, the $\mathrm{NO}_{2}$ data have to be taken with great care. Here, it has been compared with the FTIR data when available or corrected thanks to $\mathrm{HONO}, \mathrm{PAN}, \mathrm{HNO}_{3}$ measurements following the recommendation from Dunlea et al. (2007).

Besides of these monitors which are permanently connected to the chamber reactor, other monitors including $\mathrm{SO}_{2}$, $\mathrm{CO}$ and Hydrocarbon analyzers from Environment $\mathrm{SA}^{\circledR}$ and AirMOVOC $^{\mathrm{TM}}$ from AirMOTEC ${ }^{\circledR}$ are also available to be employed on CESAM platform.

\subsubsection{Fourier transform infra-red spectrometry}

An infrared analytical pathway comprising a Fourier Transform Infra-Red spectrometer (FT-IR) interfaced with a multiple path cell has been developed for trace gas measurements. The spectrometer - a Bruker ${ }^{\circledR}$ Tensor $37^{\mathrm{TM}}$ - is based on a newly patented stabilized interferometer (Simon et al., 1994). It is equipped with a liquid nitrogen cooled MCT detector and a globar source. The multiple cell - based on the original design of White (1942) - consists of an arrangement of three high reflectivity gold coated mirrors with a base length of $2 \mathrm{~m}$ which are mounted face to face on two large flanges inside the chamber reactor: one pair of circular twin mirrors of diameter of $0.2 \mathrm{~m}$ and one $0.2 \times 0.4 \mathrm{~m}$ rectangular front mirror. A good compromise between the enhancement of the signal by increasing the path length and geometrical loss or absorption by mirrors is established by adjusting the White cell to 96 single passes leading to a total path length of $192 \mathrm{~m}$. The spectrometer is mounted on a solid framework attached to the body of the chamber reactor in order to minimize any relative movement of the instrument and of the multiple reflections cell and thus minimizing the noise arising from chamber vibrations induced by pumps, mixing fan, or even by the ground. The IR beam enters and exits the reactor by passing through $\mathrm{ZnSe}$ windows. In spite of its relatively poor transmission factors compared to $\mathrm{KBr}$ windows, $\mathrm{ZnSe}$ windows have a low surface hygroscopicity which allows the chamber to be operated under very humid conditions.

To transfer the analytical beam to the white cell, two symmetric optical systems comprising several gold mirrors guide the IR beam from the spectrometer light source to the chamber entrance window and from the exit window back to the spectrometer detector. To minimize the ambient air absorption (mainly by water and $\mathrm{CO}_{2}$ ), all transfer optics as well as the spectrometer are enclosed in a transparent leak tight Altuglas ${ }^{\circledR}$ box, which is continuously flushed with dry pure nitrogen flowing at a constant rate from the evaporation of pressurized liquid nitrogen tank. 
Table 1. Instrumentation summary: the sampling time and the detection limit depending on the measured species and/or instrumental parameters and are given for references only.

\begin{tabular}{|c|c|c|c|c|}
\hline Media & Instruments/Reference & Measures & $\begin{array}{l}\text { Sampling } \\
\text { (method/time) }\end{array}$ & LDL/Accuracy \\
\hline Gas & $\begin{array}{l}\mathrm{NO}_{\mathrm{x}} \text { monitor } \\
\text { Horiba }^{\circledR} \text { APNA } 370{ }^{\circledR}\end{array}$ & $\mathrm{NO},\left(\mathrm{NO}_{2}\right)$ & $\begin{array}{l}\text { Continuous } \\
90 \mathrm{~s}\end{array}$ & $0.5 \mathrm{ppb}$ \\
\hline Gas & $\begin{array}{l}\text { Ozone monitor } \\
\text { Horiba }^{\circledR} \text { APOA } 370^{\circledR}\end{array}$ & $\mathrm{O}_{3}$ & $\begin{array}{l}\text { Continuous } \\
75 \mathrm{~s}\end{array}$ & $0.5 \mathrm{ppb}$ \\
\hline Gas & $\begin{array}{l}\mathrm{SO}_{2} \text { monitor } \\
\text { Environnement } \mathrm{SA}^{\circledR}{ }_{\mathrm{AF} 22 \mathrm{M}^{\circledR}}\end{array}$ & $\mathrm{SO}_{2}$ & $\begin{array}{l}\text { Continuous } \\
6 \mathrm{~s}\end{array}$ & $1 \mathrm{ppb}$ \\
\hline Gas & $\begin{array}{l}\text { Hygrometer } \\
\text { Vaisala }{ }^{\circledR}, \mathrm{HMP} 234^{\circledR}{ }^{\circledR}\end{array}$ & Relative Humidity & $\begin{array}{l}\text { In-situ } \\
3 \mathrm{~min}\end{array}$ & $0.1 \%$ \\
\hline Gas & $\begin{array}{l}\text { GC-MS Varian }{ }^{\circledR} \\
\text { Bechara et al. }(2008)\end{array}$ & VOCs & $\begin{array}{l}\text { Cartridges } \\
10 \text { min }\end{array}$ & $3 \mathrm{ppt}$ \\
\hline Gas & $\begin{array}{l}\text { In situ FT-IR Bruker }{ }^{\circledR} \\
\text { Tensor } 37^{\circledR}\end{array}$ & $\begin{array}{l}\mathrm{O}_{3}, \mathrm{NO}_{\mathrm{x}}, \mathrm{NO}_{\mathrm{y}} \\
\text { VOCs, OVOCss }\end{array}$ & $\begin{array}{l}\text { In situ } \\
5 \mathrm{~min}\end{array}$ & $10 \mathrm{ppb}$ \\
\hline Gas & $\begin{array}{l}\text { HONO analyzer - NitroMAC } \\
\text { Afif et al. (2010) }\end{array}$ & HONO & $\begin{array}{l}\text { Continuous } \\
5 \mathrm{~min}\end{array}$ & $3 \mathrm{ppt}$ \\
\hline Gas/Liquid & $\begin{array}{l}\text { HPLC/DNPH } \\
\text { Ferrari et al. (1999) }\end{array}$ & Carbonyl compound & $\begin{array}{l}\text { Impingers } \\
30 \mathrm{~min}\end{array}$ & $\begin{array}{l}\text { Gas } 1 \mathrm{ppb} \\
10^{-7} \mathrm{moll}^{-1} \text { in liq. }\end{array}$ \\
\hline Gas/Liquid & $\begin{array}{l}\text { HPLC/Horse radish } \\
\text { Hellpointner and Gaab (1989) }\end{array}$ & Hydroperoxides & $\begin{array}{l}\text { Impingers } \\
30 \mathrm{~min}\end{array}$ & $\begin{array}{l}\text { Gas } 1 \mathrm{ppb} \\
10^{-7} \mathrm{moll}^{-1} \text { in liq. }\end{array}$ \\
\hline Gas/Aerosol & $\begin{array}{l}\text { Ionic Chromatography } \\
\text { Dionex }{ }^{\circledR} 4500 i^{\circledR}\end{array}$ & $\begin{array}{l}\text { Organic acid, } \\
\text { sulfates }\end{array}$ & $\begin{array}{l}\text { Impingers/filters } \\
10 \mathrm{~min}\end{array}$ & $\begin{array}{l}\text { Gas } 1 \mathrm{ppb} \\
10^{-7} \mathrm{moll}^{-1} \text { in liq. }\end{array}$ \\
\hline $\begin{array}{l}\text { Aerosol } \\
\text { phase }\end{array}$ & $\begin{array}{l}\text { SMPS System } \\
\text { TSI }^{\circledR} \text { DMA model } 3080 \\
\text { TSI }^{\circledR} \text { CPC model } 3010\end{array}$ & $\begin{array}{l}\text { Aerosol size } \\
\text { distribution }\end{array}$ & $\begin{array}{l}\text { Continuous } \\
2 \mathrm{~min}\end{array}$ & $\begin{array}{l}10 \text { to } 1000 \mathrm{~nm} \\
10^{2}-10^{7} \\
\text { particles } \mathrm{m}^{-3}\end{array}$ \\
\hline $\begin{array}{l}\text { Aerosol } \\
\text { phase }\end{array}$ & $\begin{array}{l}\text { Light-scattering aerosol } \\
\text { spectrometer system } \\
\text { Palas }{ }^{\circledR} \text { Welas }{ }^{\circledR} \text { digital } 2000\end{array}$ & $\begin{array}{l}\text { Aerosol size } \\
\text { distribution }\end{array}$ & $\begin{array}{l}\text { Continuous } \\
2 \min \left(21 \mathrm{mn}^{-1}\right)\end{array}$ & $\begin{array}{l}0.2 \mu \mathrm{m} \text { to } 105 \mu \mathrm{m} \\
C_{n} \leq 10^{6} \\
\text { particles } \mathrm{cm}^{-3}\end{array}$ \\
\hline $\begin{array}{l}\text { Aerosol } \\
\text { phase }\end{array}$ & $\begin{array}{l}\text { Supercritical fluid extraction - } \\
\text { GC-MS } \\
\text { Chiappini et al. (2006) }\end{array}$ & $\begin{array}{l}\text { Chemical } \\
\text { composition of } \\
\text { organic particles }\end{array}$ & $\begin{array}{l}\text { Filters } \\
30 \mathrm{~min}\end{array}$ & $10 \mathrm{ng} /$ filter/cpnds \\
\hline $\begin{array}{l}\text { Aerosol } \\
\text { phase }\end{array}$ & $\begin{array}{l}\text { Analytical scanning electron } \\
\text { microscopy (SEM) } \\
\text { JEOL }^{\circledR} 6301 \mathrm{~F}^{\circledR}\end{array}$ & $\begin{array}{l}\text { Particle morphology } \\
\text { Elemental } \\
\text { composition }\end{array}$ & Filters & \\
\hline $\begin{array}{l}\text { Aerosol } \\
\text { phase }\end{array}$ & $\begin{array}{l}\text { Analytical transmission electron } \\
\text { microscopy (TEM) } \\
\text { JEOL }^{\circledR} 100 \mathrm{CXII}{ }^{\circledR}\end{array}$ & $\begin{array}{l}\text { Particle morphology } \\
\text { Elemental } \\
\text { composition }\end{array}$ & Filters & \\
\hline $\begin{array}{l}\text { Physical } \\
\text { Param. }\end{array}$ & $\begin{array}{l}\text { Thermometer } \\
\text { Vaisala }{ }^{\circledR} \text { HMP234 }{ }^{\circledR}\end{array}$ & Temperature & $\begin{array}{l}\text { In situ } \\
3 \mathrm{~min}\end{array}$ & -20 to $50^{\circ} \mathrm{C}$ \\
\hline $\begin{array}{l}\text { Physical } \\
\text { Param. }\end{array}$ & $\begin{array}{l}\text { Pressure gauges } \\
\text { MKS }^{\circledR} \text { Baratrons 622A }{ }^{\circledR} \\
\text { MKS }^{\circledR} \text { Baratrons 626A }{ }^{\circledR} \\
\text { Leybold Inficon }{ }^{\circledR}\end{array}$ & Pressure & $\begin{array}{l}\text { In situ } \\
10 \mathrm{~s}\end{array}$ & $0.25 \%$ \\
\hline $\begin{array}{l}\text { Physical } \\
\text { Param. }\end{array}$ & $\begin{array}{l}\text { Spectroradiometer } \\
\text { Licor }{ }^{\circledR} \text { LI- } 1800^{\circledR}\end{array}$ & Actinic flux & $5 \mathrm{~min}$ & $\begin{array}{l}300-800 \mathrm{~nm} \\
\text { resolution } 3 \mathrm{~nm}\end{array}$ \\
\hline
\end{tabular}


The FT-IR system records spectra in the infrared range between 500 and $4000 \mathrm{~cm}^{-1}$ with an optimal resolution of $0.5 \mathrm{~cm}^{-1}$. Typical experiment leads to the acquisition of hundreds of FTIR spectra. To perform the analysis of such huge datasets, an home made software has been written to perform the singular value decomposition of the matrix built from the global absorbance over each spectral elements and from the pure response (the reference spectra) of the $\mathrm{n}$ mixture components (up to 15 compounds). The deconvolution process is performed following a scalar decomposition method described as the K-matrix of Lambert-Beer's law in Griffiths and De Haseth (1986). This procedure leads to the concentration of the $\mathrm{n}$ suspected compounds from each experimental spectrum. It has been proven to be fast and reliable providing that no major reference spectrum are missing for the considered spectral range. Our software is currently being intercompared with other tools (Rodènas et al., 2010) and more general information about the characteristic of these methods can be found in Griffiths and De Haseth (1986) or De Juan and Tauler (2003). In any case, for each experiment, the results from this automatic procedure are cross-checked by manual substraction performed over selected spectra.

Typical detection limits in absorption spectra recorded by co-adding 100 scans (i.e. with an integration time of $5 \mathrm{~min}$ ) for various gaseous compounds are given as follows: $\mathrm{NO}_{2}$ (5 ppb), Ozone (5 ppb), PAN (5 ppb), HCHO (3 ppb), propene (20 ppb), and $\mathrm{HNO}_{3}(10 \mathrm{ppb})$.

\subsubsection{Others - chemical analysis}

Nitrous acid is monitored at low concentration using $\mathrm{Ni}$ troMAC, a home-made instrument (Afif et al., 2011). It is based on a wet chemical sampling and HPLC-VIS detection. The sampling process is realized by dissolution of the gaseous HONO in a buffer phosphate solution followed by a derivatization with SA/NED (sulphanilamide/N(1-naphthyl)-ethylenediamine). The short HPLC analysis time of 5 min allows a measurement every $10 \mathrm{~min}$ with a detection limit of a few ppt.

For carbonyl species measurements, the method of impinger sampling in DNPH solution described by Ferrari et al. (1999) is used. The chemical derivatization products are analyzed by HPLC coupled to UV detection at $360 \mathrm{~nm}$. This technique gives access to a detection limit of ca. $0.1 \mathrm{ppb}$ for most carbonyls with a sampling volume of 1001 .

\subsection{Aerosol phase measurements}

\subsubsection{Scanning mobility particle sizer}

A Scanning Mobility Particle Sizer comprising a Differential Mobility Analyzer (TSI ${ }^{\circledR}$, model 3080) coupled with a Condensation Particle Counter (TSI ${ }^{\circledR}$, model 3010), is used to monitor the sub-micrometer particle number concentration and size distribution. The sampling flow rate of this system is of $21 \mathrm{~min}^{-1}$ and a continuous fast-scanning technique provides a high-resolution measurement. A full size distribution scanning ranging from 10 to $500 \mathrm{~nm}$ or 20 to $850 \mathrm{~nm}$ can be obtained within two minutes. By considering the condensation counter characteristics and the sampling set-up, the measurement dynamic range goes from 150 to $10^{7}$ particles $\mathrm{cm}^{-3}$.

\subsubsection{Optical particle counter}

For the measurement of particles and droplets larger than $1 \mu \mathrm{m}$ in the chamber reactor discussed in this study (see later), a Grimm ${ }^{\circledR} 1.108$ SubMicron Aerosol Spectrometer is used with a particle sampling rate of $1 \mu \mathrm{m}$ to $20 \mu \mathrm{m}$ over a dynamic range of counts going from 1 to $2 \times 10^{6}$ counts $1^{-1}$. Recently, this instrument was replaced by a Palas ${ }^{\circledR}$ Welas digital $2000^{\mathrm{TM}}$. This latter instrument is a White lightscattering spectrometer, which determines the particle concentration from $<1$ particle $\mathrm{cm}^{-3}$ to $10^{6}$ particles $\mathrm{cm}^{-3}$ and the particle size over 256 channels ranging from $200 \mathrm{~nm}$ to $105 \mu \mathrm{m}$. As the sensor itself is connected to the spectrometer with fibre-optic cables, it has been attached directly to the chamber reducing to the minimum the transfer tubing (i.e. less than $5 \mathrm{~cm}$ ) and hence the risk of particle loss. Furthermore, the instrument has been modified by the manufacturer to allow a smaller sampling rate $\left(21 \mathrm{mn}^{-1}\right)$ than the standard product $\left(51 \mathrm{mn}^{-1}\right)$.

\section{Chamber performances qualification and testing}

\subsection{Vacuum and sealing performances}

It is known that the chemical transformations of atmospheric pollutants often lead to the formation of heavy and polar compounds which may have low vapor pressures. To minimize the memory effects caused by the chamber walls deposition of these heavy compounds which may consequently affect the experimental results, it is of critical importance to have an efficient chamber cleaning between experiments. The cleaning procedure carried out in CESAM is based on the reactor evacuation.

As a consequence, vacuum capabilities of the CESAM chamber may impact on the reliability of the experiments. While it may depend on the leak rate of the devices connected to the chamber, we report here typical values that were determined during specific tests as well as during several experiments already performed. The limit vacuum of CESAM falls in the range of $6 \times 10^{-4}$ mbar. As shown in Fig. 2, the time needed to reach this value is about half an hour. From the atmospheric pressure the screw pump can perform an evacuation at a rate of $4 \mathrm{mbar} \mathrm{s}^{-1}$ corresponding to a pumping speed of $201 \mathrm{~s}^{-1}$. This is a critical parameter for performing a rapid expansion in the chamber for the need of cloud droplet generation which will be discussed later. In the range of a few 
hundred mbar this value is further increased to ca. $501 \mathrm{~s}^{-1}$ when the root pump reaches its maximum efficiency.

The chamber leak rate has been determined by monitoring the pressure increase from the limit vacuum by the sole action of leaks. In the low pressure range, it has been found equal to $1.5 \times 10^{-2} \mathrm{mbar} \mathrm{h}^{-1}$ which is fairly good for such a large reactor. From this value and considering that the filling process lasts about half an hour, less than $7 \mathrm{ppm}$ of ambient air outside of the chamber may be introduced into the chamber during the preparation period. This estimation must be considered as an upper limit as the leak rate decreases during the filling process in proportion of the difference between the chamber pressure and the lab pressure.

\subsection{Mixing}

A good gas and particle mixing is required for the investigations in simulation chambers. For gas phase chemistry, as most of chemical kinetic rate constants are directly proportional to the reactant concentrations, inhomogeneous concentrations can lead to false experimental data and/or strongly complicate their modeling. For particle phase studies, as condensation of semi-volatiles is highly non-linear with concentration, insufficient mixing can lead to an incorrect estimation of secondary organic aerosol yields caused by a local supersaturation. Furthermore, a good mixing will also lead to better temperature homogeneity of the chamber. It may also influence the wall exchanges (i.e. the lifetime of gaseous and particulate species).

The gas phase mixing time as well as the influence of the positions of injection and sampling lines have been tested. To do so, an inert gas - carbon monoxide - was used as a tracer. It was injected into the chamber at atmospheric pressure and $20 \pm 2{ }^{\circ} \mathrm{C}$ and monitored by using using an Infrared gas filter correlation $\mathrm{CO}$ monitor (Environnement $\mathrm{SA}{ }^{\circledR}, \mathrm{CO}_{2} \mathrm{M}^{\mathrm{TM}}$, France) with a sampling flow rate of $11 \mathrm{~min}^{-1}$. The inlet line was either extended inside the chamber near the fan (Fig. 3), or mounted on a large port at the side of the reactor body.

Figure 3 shows that the tracer injected in the chamber can be considered as well-mixed in less than $60 \mathrm{~s}$. This result has been found to be relatively insensitive to the injection position. This mixing time is relatively short comparing to experiment durations which may last for several hours. As a consequence, inhomogeneity may be considered to be negligible if the pseudo-first order rate constant of the considered process is smaller than $2 \times 10^{-3} \mathrm{~s}^{-1}$ (ten times slower than mixing) which is achieved in most cases. Nevertheless, when designing experiments, one will have to take into account this major feature of the chamber in the choice of reactant concentrations.

In order to rationalize these results computer simulations were carried out by using the Facsimile ${ }^{\mathrm{TM}}$ software package (Curtis, 1979). One of the objectives was also to calculate the average gas speed in the chamber which is a parameter of interest for future heterogeneous chemistry studies involv- ing materials exposed in the chamber. To do so, the chamber was numerically divided into 4137 cubic cells exchanging between themselves with homogeneous first-order rate. In short, an isotropic mixing was assumed and the exchange rate was adjusted to allow the modeled concentration at the measurement location to fit with the recorded data. For the experiments modeled, injection locations were taken into account by considering an instantaneous injection in the corresponding cells.

As it can be observed on Fig. 3, this rather simple approach led to fair agreement considering that the injection rate was not taken into account and that the dynamics are probably different near the flanges that in the chamber volume. These calculations led to a first-order exchange rate equal to $3 \pm 0.5 \mathrm{~s}^{-1}$ which corresponds to an average speed of the gases equal to $0.3 \mathrm{~m} \mathrm{~s}^{-1}$ when the fan is operated at full speed. Additional calculations were performed for slower fan operating rates and the results are given in Table 2.

\subsection{Irradiation spectra and light homogeneity}

Lighting realism and stability are probably among the most critical factors which can affect results from chamber runs. This is particularly true for indoor simulation chambers where the artificial light sources may exhibit emission spectra quite different from the solar spectrum. It must be noted here that outdoor chambers may also suffer from lighting stability issues due to changes in the zenith angle, weather modifications or variation in the particle contents of air which may sometimes complicate the interpretation of outdoor chamber experiments. This idea was particularly raised by Carter (1995) and by Winer et al. (1979) who have shown to which extent it can affect the reliability of the simulations.

Among the artificial light sources, high-pressure xenon arc lamps provide the most faithful artificial reproduction of solar energy distribution at the earth's surface in wavelength region of 290-700 nm (Calvert and Pitts, 1966).

In order to validate the CESAM irradiation system, both the absolute light intensity and its spectral distribution have been carefully characterized. In CESAM, the irradiance spectra were measured directly by using a portable spectroradiometer LICOR-1800.

The comparison of xenon arc lamps radiation spectrum (dashed line) with solar spectrum (solid line, $45^{\circ} \mathrm{N}, 21$ June, 12:00 ST, $0 \mathrm{~km}$ ) calculated by the TUV model (TUV NCAR - Madronich and Flocke, 1999) is shown in Fig. 4. It can be seen that the xenon lamp spectrum shows an extra light intensity below $300 \mathrm{~nm}$ which is generally considered as a critical spectral region for atmospheric photochemical chemistry. Indeed, high energy radiation can induce different mechanisms in photosmog formation system at ground level. To prevent unrealistic chemistry, Pyrex ${ }^{\circledR}$ plates were mounted between the lamps and the chamber windows to filter radiation below $300 \mathrm{~nm}$. To determine the characteristic of these optical 

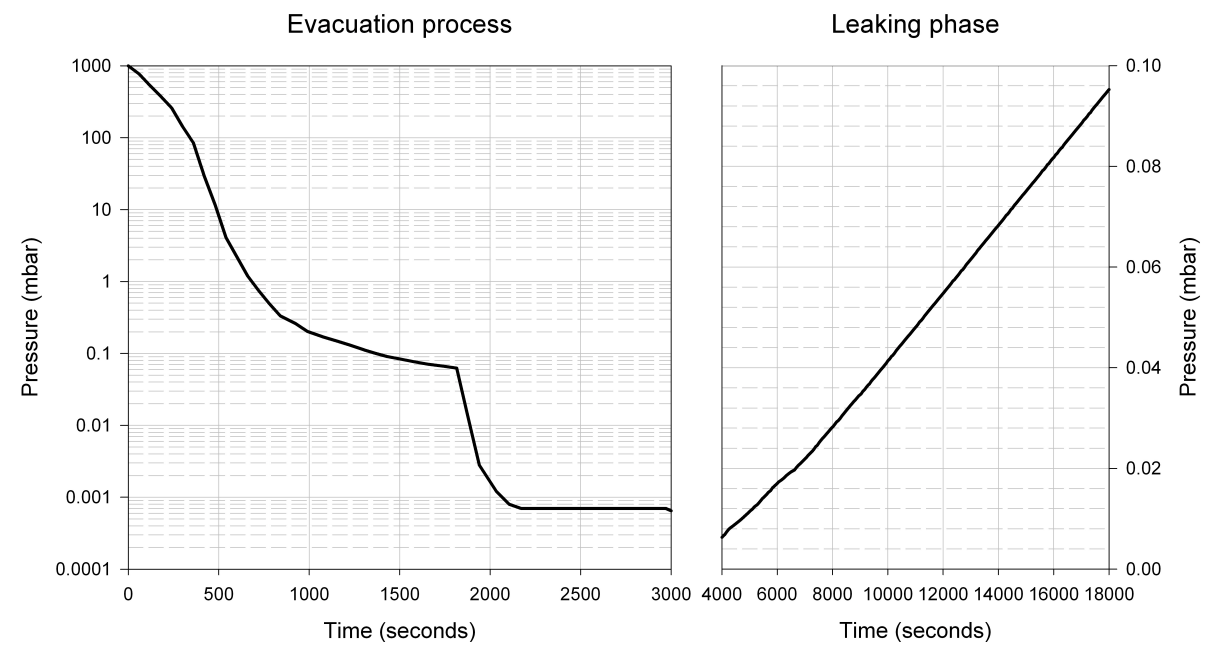

Fig. 2. CESAM chamber absolute pressure plotted against time during a pumping phase (left panel) and the leak rate determination (right panel).

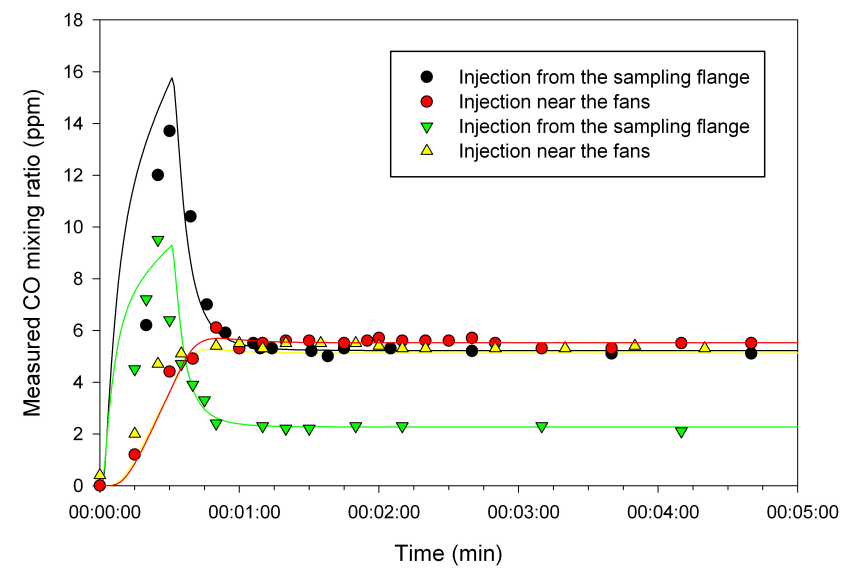

Fig. 3. Concentration-time evolution of CO near the sampling point after injection in the chamber from various injection ports. The lines are the results of the modeling for corresponding experiment.

filters, Pyrex plates of various thicknesses were studied. The corresponding xenon spectra are shown in Fig. 4.

Pyrex filters of $9 \mathrm{~mm}$ thickness were eventually adopted and allowed us to record the radiation spectrum which is very close to the solar spectrum at the ground level. To rationalize the comparison of the spectra inside CESAM and the solar irradiation, we propose to use the ratio of photolysis frequencies of two important atmospheric processes:

$$
\begin{aligned}
& \mathrm{NO}_{2}+h v \rightarrow \mathrm{NO}+\mathrm{O}^{3} \mathrm{P} \\
& \mathrm{O}_{3}+h v \rightarrow \mathrm{O}_{2}+\mathrm{O}^{1} \mathrm{D}
\end{aligned}
$$

The ratios of photolysis frequency $J_{\mathrm{NO}_{2}}$ to $J_{\mathrm{O}^{1} \mathrm{D}}$ are thereby considered as indicators to qualify radiation system, where $J_{\mathrm{NO}_{2}}$ and $J_{\mathrm{O}^{1} \mathrm{D}}$ represent light intensity in spectral region
Table 2. Correlation table between mixing time and modeled average speed of gases in the CESAM chamber.

\begin{tabular}{lll}
\hline $\begin{array}{l}\text { Mixing } \\
\begin{array}{l}\text { Time } \\
(\mathrm{s})\end{array}\end{array}$ & $\begin{array}{l}\text { First order } \\
\text { mixing rate } \\
\left(\mathrm{s}^{-1}\right)\end{array}$ & $\begin{array}{l}\text { Average gases } \\
\text { speed } \\
\left(\mathrm{m} \mathrm{s}^{-1}\right)\end{array}$ \\
\hline 60 & 3 & 0.3 \\
100 & 2 & 0.2 \\
150 & 1 & 0.1 \\
300 & 0.5 & 0.05 \\
500 & 0.3 & 0.03 \\
\hline
\end{tabular}

UV-A and UV-B respectively. Photolysis frequencies $(J)$ were calculated by using the cross sections from Voigt et al. (2001) for $\mathrm{NO}_{2}$ and from Molina and Molina (1986) for ozone. The quantum yields for ozone and $\mathrm{NO}_{2}$ are from DeMore et al. (1994). Irradiance spectra taken with and without Pyrex filters with the LICOR LI-1800 instrument were then converted into actinic flux. This was achieved by taking into account the fact that the actinic light in the chamber includes direct light from the beam and reflected light from the polished wall. This latter source was assumed to be isotropic which is supported by the multiple reflections that occur in the chamber. To perform this conversion accordingly with the principles formalized by Madronich (1987), it was necessary for each measurement to acquire the spectrum of the downward light including the direct light coming from the lamps and the upward spectrum assumed as representative of the reflected light. These irradiance spectra were then converted into a single actinic flux spectrum by combining them taking into account pseudo-zenithal angles from geometrical calculations in the chamber. 


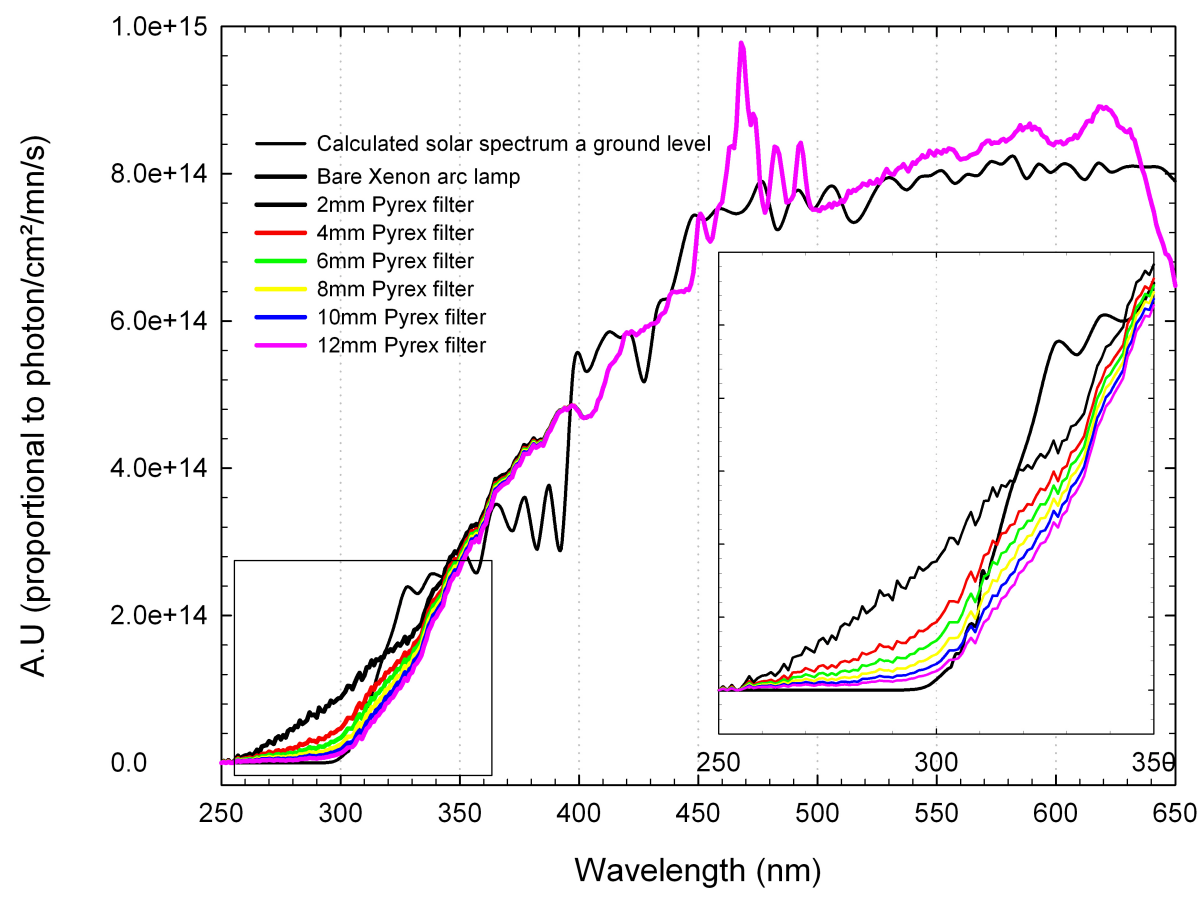

Fig. 4. Comparison of irradiation spectra. The thin black curve is solar spectrum calculated from TUV NCAR, 12 h, Equator, 21 June. The thick color curves are spectra of xenon filtered by different thicknesses of Pyrex films (the solar spectrum is scaled to the lamps spectra to facilitate comparison of their shapes).

Table 3. $J_{\mathrm{NO}_{2}} / J_{\mathrm{O}^{1} \mathrm{D}}$ of xenon lights filtered by different thicknesses Pyrex filters determined in the CESAM chamber and of solar light at different altitudes (data taken from TUV/NCAR, $12 \mathrm{~h}, 21$ June at the equator).

\begin{tabular}{|c|c|c|c|}
\hline Xenon-4KW & $\begin{array}{l}9 \text { mm Pyrex } \\
\text { filter }\end{array}$ & $\begin{array}{l}2 \text { mm Pyrex }{ }^{\circledR} \\
\text { filter }\end{array}$ & No filter \\
\hline$J_{\mathrm{NO}_{2}} / J_{\mathrm{O}^{1} \mathrm{D}}$ & 298.0 & 3.2 & 2.0 \\
\hline Solar & Ground level & $45 \mathrm{~km}$ altitude & $60 \mathrm{~km}$ altitude \\
\hline$J_{\mathrm{NO}_{2}} / J_{\mathrm{O}^{1} \mathrm{D}}$ & 260.0 & 3.3 & 2.0 \\
\hline
\end{tabular}

Table 3 shows the ratios $\left(J_{\mathrm{NO}_{2}} / J_{\mathrm{O}^{1} \mathrm{D}}\right)$ of chamber radiation for different thickness of Pyrex filters measured in CESAM chamber and $J$ of solar light calculated at different altitudes. According to Fig. 4 and Table 3, there is an excellent relative agreement between the chamber radiation system with $9 \mathrm{~mm}$ Pyrex filter and the solar light at the ground level. Furthermore, by changing the Pyrex filter thickness, it is possible to mimic solar light at various altitudes, which could be of potential interest for future studies relevant for the upper atmosphere.

Single point spectroradiometric determinations of $J_{\mathrm{NO}_{2}}$ and $J_{\mathrm{O}^{1} \mathrm{D}}$ performed with the LICOR ${ }^{\mathrm{TM}} \mathrm{LI}-1800^{\circledR}$ placed at the bottom in the middle of the chamber led to values respec- tively equal to $4.5 \times 10^{-3} \mathrm{~s}^{-1}$ and $1.5 \times 10^{-5} \mathrm{~s}^{-1}$. While these values must be taken with care due to possible inhomogeneity of the light, it can be compared with the value calculated by the TUV/NCAR model for a equatorial location on 21 June at noon which led to $1.27 \times 10^{-2} \mathrm{~s}^{-1}$ and $4.8 \times 10^{-5} \mathrm{~s}^{-1}$.

Simulation chamber experiments require a good homogeneity of the irradiation flux. Indeed, inhomogeneity may lead to biased photochemical effects such as local higher or lower radical levels. To characterize the irradiation homogeneity, a network of BS520 Sharp ${ }^{\circledR}$ photodiodes was set up. These low cost photodiodes exhibit a high sensitivity greater than $70 \%$ for wavelength from 450 to $650 \mathrm{~nm}$ which overlaps nicely the atmospheric visible spectrum. The photodiodes were cross calibrated in the sunlight together with the LICOR signal. The photodiode array was installed at nine different levels in the chamber and the signal was recorded both with photodiode field of view turned towards the top of the chamber and towards the bottom. These two measurements giving access respectively to direct and reflected light flux and reflected flux alone were then combined to produce nine tomography slices shown in Fig. 5.

Experimental data show that the light flux can vary by a factor 5 from well irradiated to less irradiated locations in the reactor. This is undoubtedly a negative consequence of the technical choices which led us to adopt lighting from points sources design by contrast with many sources surrounding a transparent reactor such as what has been adopted in other 


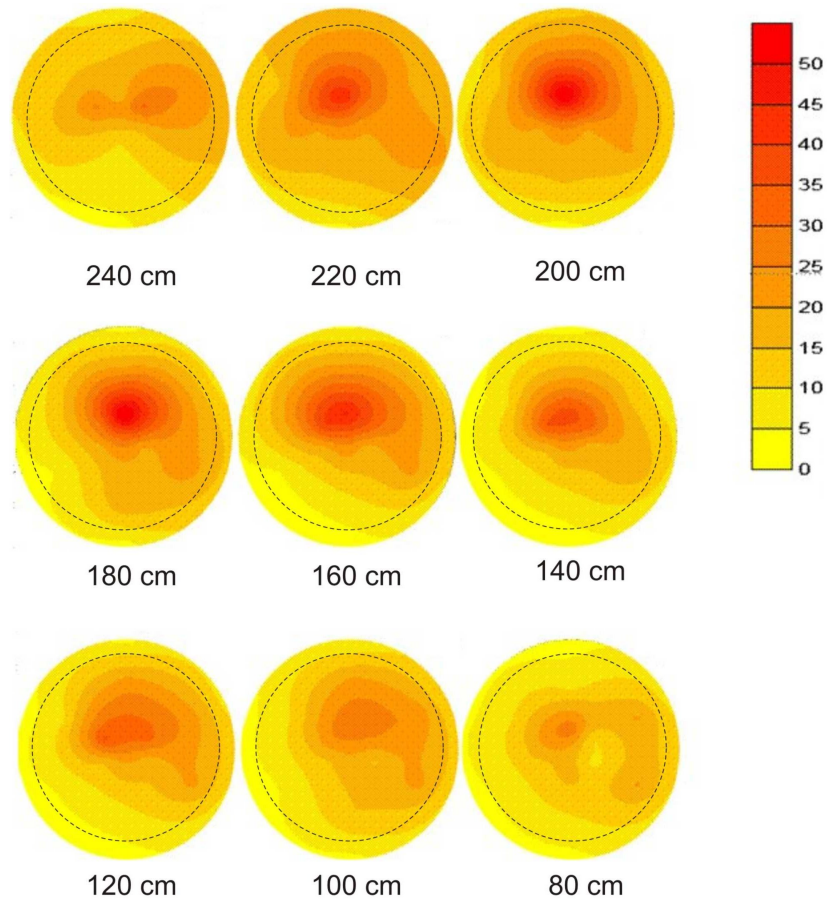

Fig. 5. Light intensity homogeneity measurements inside the chamber in arbitrary unit. Each disk represents one horizontal section measurement. The first section (top-left) was measured at the lowest level of the chamber. Indicated lengths are the vertical distance between the considered slice and the horizontal plane defined by the three arc-lamps. Note: inside the dash-lined circle, the contour plots have been created by interpolation between measurements. Outside the dashed line, values are not measured but extrapolated.

chamber designs (Doussin et al., 1997; Thuner et al., 2004). It should be pointed out that this disadvantage can be compensated by the possibility offered by such an arrangement to filter the light and hence to perform quantum yield studies with the help of pass band filters or high altitude photochemistry with the help of thinner filters (see above).

However, thanks to the mixing fan, the impact of irradiation inhomogeneity can be considered negligible for a photochemical reaction whose photolysis frequency is smaller than $10^{-2} \mathrm{~s}^{-1}$ in the bright parts of the chamber. On the contrary, for fast photochemical reactions, the impact of radiation inhomogeneity will have to be taken into account as an internal variability.

\section{Cleaning procedure}

Gas-phase compounds like $\mathrm{NO}_{\mathrm{z}}$ and heavy hydrocarbons, as well as aerosols may be adsorbed on the chamber inner walls and induce memory effects which would affect data accuracy and reproducibility. In routine mode, i.e. after each experiment, a chamber clean-up is performed by evacuation to the maximum vacuum for at least one hour but usually overnight. Besides the high-vacuum technique, the reactor is also regularly cleaned-up by injecting large quantity of ozone (up to to $200 \mathrm{ppm}$ ) in the chamber. Since ozone is a very oxidative compound, impurities attached to the chamber walls can be possibly chemically degraded from the surface and ultimately eliminated by vacuum. Occasionally, the chamber reactor can also be manually cleaned-up by flushing large quantity of ultrapure water and by wiping the walls with pure ethanol.

\subsection{Chemical characterization experiments}

In order to characterize the chemical properties of the CESAM facility, such as the overall photolysis frequency or heterogeneous wall reactions for main species involved in the photosmog air pollution, a set of dedicated experiments have been carried out.

For each run, gaseous reactant introduction is conducted either by an accurate gas syringe injection through a septum valve, or by flushing a known pressure of reactant prepared in a glass bulb of known volume. For each of the following experiment, the chamber was cleaned under secondary vacuum for at least one hour and then filled with synthetic air. During this set of experiments, the three xenon lamps equipped with the Pyrex ${ }^{\circledR}$ filter of $9 \mathrm{~mm}$ were used at full power, and the mixing fan was always kept on.

All runs were conducted in a synthetic air produced from the mixture of ca. $200 \mathrm{mbar}$ of $\mathrm{O}_{2}$ (Air Liquide ${ }^{\circledR}$, Alphagaz ${ }^{\circledR}$ class 1) and ca. 800 mbar of nitrogen produced from the evaporation of a pressurized liquid nitrogen tank.

It must be indicated that this nitrogen source is economic and free from trace gas VOCs or $\mathrm{NO}_{\mathrm{x}}$, but exhibits a contamination of ca. $1 \mathrm{ppm}$ of carbon monoxide. However, due to its slow reactivity compared to atmospheric processes and its very high vapor pressure this was not considered as a major inconvenience neither for ozone production studies nor for aerosol chemistry studies. It was, hence, considered of minor importance with respect to the experiment objectives. Nevertheless, $\mathrm{CO}$ concentration was determined during each experiment by FT-IR spectroscopy and the chemistry induced due to its presence is taken into account in the data interpretation.

All experiments were under dry conditions (relative humidity was lower than $1 \%$ ) and atmospheric pressure. Temperature was maintained at $293 \pm 2 \mathrm{~K}$.

\subsection{1 $\mathrm{NO}_{\mathrm{x}}$-air experiments}

Considering the radiation inhomogeneity as discussed previously, spectroradiometric measurements are often not able to provide satisfying absolute light intensity estimation for the whole chamber. Chemical actinometry is thereby considered as a more integrative method to determine the mean light intensity and to estimate the photolysis frequency of compounds like $\mathrm{NO}_{2}\left(J_{\mathrm{NO} 2}\right)$ and ozone $\left(J_{\mathrm{O}^{1} \mathrm{D}}\right)$. Furthermore, in addition to the determination of these photolysis frequencies of major atmospheric importance, it is necessary to 


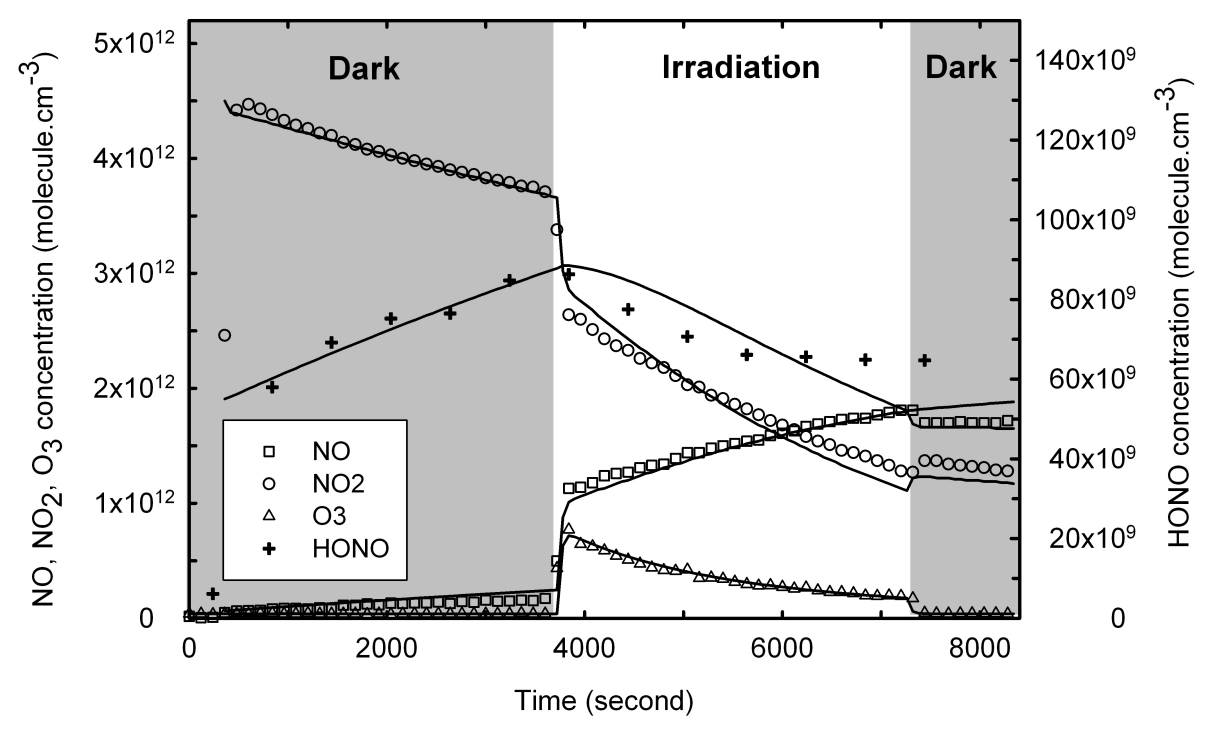

Fig. 6. $\mathrm{NO}_{\mathrm{x}}$ /air/light system investigation in the CESAM chamber: comparison of simulated (solid lines) and experimental concentrations (symbols) of $\mathrm{NO}, \mathrm{NO}_{2}$, ozone and $\mathrm{HONO}$ as a function of time.

investigate the reproducibility of the behavior of the nitrogen oxides and their photochemical by-products in the chamber. Indeed, it is well known for chamber investigations that the walls are not completely chemically inert to gaseous species, especially for compounds like nitrogen oxides. The photooxidation of $\mathrm{NO}_{\mathrm{x}}$ mixtures is then a necessary step to build an auxiliary mechanism which will help in the description of the wall reactivity and can be used as a dataset for future computer modeling of experimental runs. The photo-oxidation of $\mathrm{NO} / \mathrm{NO}_{2}$ mixtures in ambient air has been widely used to characterize simulation chambers (Obrien, 1974; Carter et al., 1979; Doussin et al., 1997; Bloss et al., 2005; Hynes et al., 2005; Metzger et al., 2008). A set of experiments was carried out to investigate the photochemistry of nitrogen oxides in the CESAM chamber. Four experiments were conducted by using $\mathrm{NO}_{2}$ (Air Liquide ${ }^{\circledR}$, Alphagaz ${ }^{\circledR} 99.9 \%$ purity) as the starting $\mathrm{NO}_{\mathrm{x}}$ load with initial concentrations ranging between 50 and $150 \mathrm{ppb}$.

Figure 6 shows the experimental concentration-time profiles for $\mathrm{NO}_{\mathrm{x}}$ and $\mathrm{O}_{3}$ for one of the experiments performed $\left(\mathrm{NO}_{2} / \mathrm{NO}\right.$ ratio $\left.=20\right)$. Each run comprises two dark periods (at the beginning and at the end of the experiments) in order to evaluate the dark reactivity of reactants on the wall and related products. A slow decrease of $\mathrm{NO}_{2}$ in the dark was correlated with a slower NO and HONO increases. As no known gas-phase mechanism can explain this chemical transformation, this behavior indicates some reducing properties of the chamber walls which can be easily explained by the metallic nature of the chamber body. Furthermore, for experiments during which $\mathrm{NO}$ was injected at first, it exhibited a fairly good stability in the chamber, showing the non oxidative property of the walls. As soon as the xenon lamps were turned on, a fast decrease of $\mathrm{NO}_{2}$ concentration was observed while ozone and NO were produced. After less than $5 \mathrm{~min}$, the photo-stationary state arising from the following sequence of reactions is reached.

$$
\begin{array}{ll}
\mathrm{NO}_{2}+h v \rightarrow \mathrm{NO}+\mathrm{O}^{3} \mathrm{P} & J_{\mathrm{NO}_{2}} \\
\mathrm{O}^{3} \mathrm{P}+\mathrm{O}_{2} \rightarrow \mathrm{O}_{3} & k_{3} \\
\mathrm{O}_{3}+\mathrm{NO} \rightarrow \mathrm{NO}_{2}+\mathrm{O}_{2} & k_{4}
\end{array}
$$

When the photo-stationary state is reached, the slow $\mathrm{NO}_{2}-$ to-NO conversion on the walls is driving all the chemistry and leads to a subsequent decrease of $\mathrm{O}_{3}$ as, from the quasistationary state equation, the ratio $\left[\mathrm{NO}_{2}\right] /\left([\mathrm{NO}] .\left[\mathrm{O}_{3}\right]\right)$ has to remain constant (Finlayson-Pitts and Pitts Jr., 1986).

In order to determine the photolysis frequency of the key species involved in this system and to better rationalize the heterogeneous wall reactions deduced from the timeconcentration curves, a kinetic numeric model of the $\mathrm{NO}_{\mathrm{x}}$ photo-oxidation system was built by using the chemical reactions and the kinetic parameters gathered and evaluated by Atkinson et al. (2004, 2006, 2007). 36 chemical reactions including 7 photochemical reactions were introduced in the model (see Supplement for an exhaustive list). The fitting properties and sensitivity analysis features of the Facsimile ${ }^{\circledR}$ numerical package (Curtis, 1979) were used for these simulations. At first, this chemical scheme was not able to reproduce the observations. In particular, the $\mathrm{NO}_{2}$-to- $\mathrm{NO}$ conversion and the HONO build-up were obviously requiring additional processes. Similar behavior in reactors have been described by Finlayson-Pitts et al. (2003) who rationalized observations from various studies in various reactors by invoking $\mathrm{N}_{2} \mathrm{O}_{4}$ reaction with adsorbed water on surfaces. In our 
Table 4. Chemical reactions introduced in the numeric model for simulating the experimental observations.

\begin{tabular}{llll}
\hline Reactions & & constants & Note \\
\hline $\mathrm{NO}_{2} \rightarrow \mathrm{NO}_{2}$ Wall & $\mathrm{R} 5$ & $2.2 \times 10^{-3} \mathrm{~s}^{-1}$ & Indicative value only \\
$\mathrm{NO}_{2}$ Wall $_{\mathrm{NO}_{2}}$ & $\mathrm{R} 6$ & $1.0 \times 10^{-1} \mathrm{~s}^{-1}$ & Indicative value only \\
$\mathrm{NO}_{2} \leftrightarrows \mathrm{NO}_{2}$ Wall & & 46 & $\begin{array}{l}\text { Fast equilibrium: only the } \\
\text { ratio } k_{5} / k_{-6} \text { was determining }\end{array}$ \\
& & & $\alpha=0.34$ and $\beta=0.07$ \\
$\mathrm{NO}_{2 \_ \text {Wall } \rightarrow \alpha \mathrm{NO}+\beta \mathrm{HONO}}$ & $\mathrm{R} 7$ & $2.0 \times 10^{-3} \mathrm{~s}^{-1}$ & $\alpha=0.10$ \\
$\mathrm{NO}_{2}$ Wall $+h v \rightarrow \delta \mathrm{NO}+\gamma \mathrm{HONO}$ & $\mathrm{R} 8$ & $1.4 \times 10^{-2} \mathrm{~s}^{-1}$ & $\delta=0.51$ and $\gamma=0.10$ \\
$\mathrm{O}_{3} \rightarrow \mathrm{O}_{3}$ Wall & $\mathrm{R} 9$ & $3.0 \times 10^{-4} \mathrm{~s}^{-1}$ & \\
\hline
\end{tabular}

case, the experiments were carried out under dry conditions and the determination of the quantity of water molecule on surfaces was not possible. Several plausible auxiliary mechanisms were tested including those proposed in the literature (Doyle, 1970; Jeffries et al., 1976; Akimoto et al., 1979b; Carter, 2000, 2006; Bloss et al., 2005; Carter et al., 2005; Hynes et al., 2005; Metzger et al., 2008). Eventually, five non-elementary hypothetical reactions were added (see Table 4) which form a chemical system based on a fast adsorption equilibrium of $\mathrm{NO}_{2}$ on the walls followed by subsequent reaction into HONO or NO. This last process was found to be light-dependent and a photocatalytic-like reductive process was assumed to contribute to the whole phenomenon. The rate constants were then adjusted in order to allow the modeled concentrations to fit observations.

The comparison of experimental and simulated concentration-time profiles of $\mathrm{NO}, \mathrm{NO}_{2}$, ozone and HONO is shown on Fig. 6. All simulated data including HONO are in very good agreement within the experimental observations for all runs of this set of experiments.

From Fig. 6, it seems obvious that the decrease of $\mathrm{NO}_{2}$ in the dark is due to an unknown mechanism which may possibly be explained by heterogeneous wall reactions as mentioned before. Reactions (R5) and (R6) are thus proposed to describe this phenomenon which was observed during all runs. In the dark, equilibrium of $\mathrm{NO}_{2}$ between gas phase and chamber walls is expected to be reached in a short time. The decrease of $\mathrm{NO}_{2}$ in the gas phase observed during the experiments can then be explained by an additional production pathway for NO and HONO on chamber walls which lead to a shift in the equilibrium. It should be pointed out that this artifact is not typical of most other existing chambers. On the contrary, most simulations chambers made of Teflon films (often slightly coated with oxidized materials from previous experiment) exhibits wall effects which have the tendency to oxidize species and singularly to transform $\mathrm{NO}$ into $\mathrm{NO}_{2}$. This unusual reductive character is not necessarily a defect and can be considered as a complementary feature of the CESAM chamber with respect to most other simulation facilities as long as it is well parameterized.
In addition, experiments where final ozone concentrations were sufficiently high to prevent full titration by $\mathrm{NO}_{\mathrm{x}}$ allowed us to observe a slow ozone decrease in the dark. Furthermore, experiments with ozone alone in the chamber led to the same observation. An ozone wall-loss Reaction (R9) was thus introduced into the numeric model. The ozone decay rate was found to be unusually high for all runs of this set, with a value of $3.0 \times 10^{-4} \mathrm{~s}^{-1}$ (see below for the discussion of the ozone wall loss rate).

Furthermore, considering the mechanism proposed by Finlayson-Pitts et al. (2003) a systematic study at various relative humidity will be performed in a near future. In any case, control runs will have to be performed regularly to better account for the possible variability of this phenomenon.

As the photo-stationary state is reached in ca. $5 \mathrm{~min}$, the determination of $J_{\mathrm{NO}_{2}}$ was only weakly affected by heterogeneous reaction discussed above.

The fitting of modeled values to the measured data led to $\mathrm{NO}_{2}$ photolysis frequency equal to $(4.2 \pm 0.2) \times 10^{-3} \mathrm{~s}^{-1}$. This value which can be considered as an average over the whole chamber volume is in good agreement with the single point spectroradiometer determination presented earlier $\left(4.5 \times 10^{-3} \mathrm{~s}^{-1}\right)$. This confirms the fact that the irradiation intensity in the CESAM chamber is about one third of the maximum light available at the equator (on 21 June at noon). On another hand, this value is approximately equal to the $24 \mathrm{~h}$-average of $J_{\mathrm{NO}_{2}}$ in the atmosphere which facilitates the transposition of photochemical lifetimes in CESAM to lifetimes in the atmosphere.

\subsubsection{Wall losses of gases}

The presence of walls is obviously one of the main structural shortcomings of simulation chambers. Indeed, throughout an experiment, vapors are inevitably lost to the chamber walls. Moreover, wall-promoted processes are obviously related to the extent of these losses. Therefore, when modeling is used as interpreting tool for the analysis of chamber experiments, loss processes have to be implemented at their suitable rate in the chemical schemes used. While the importance of these 


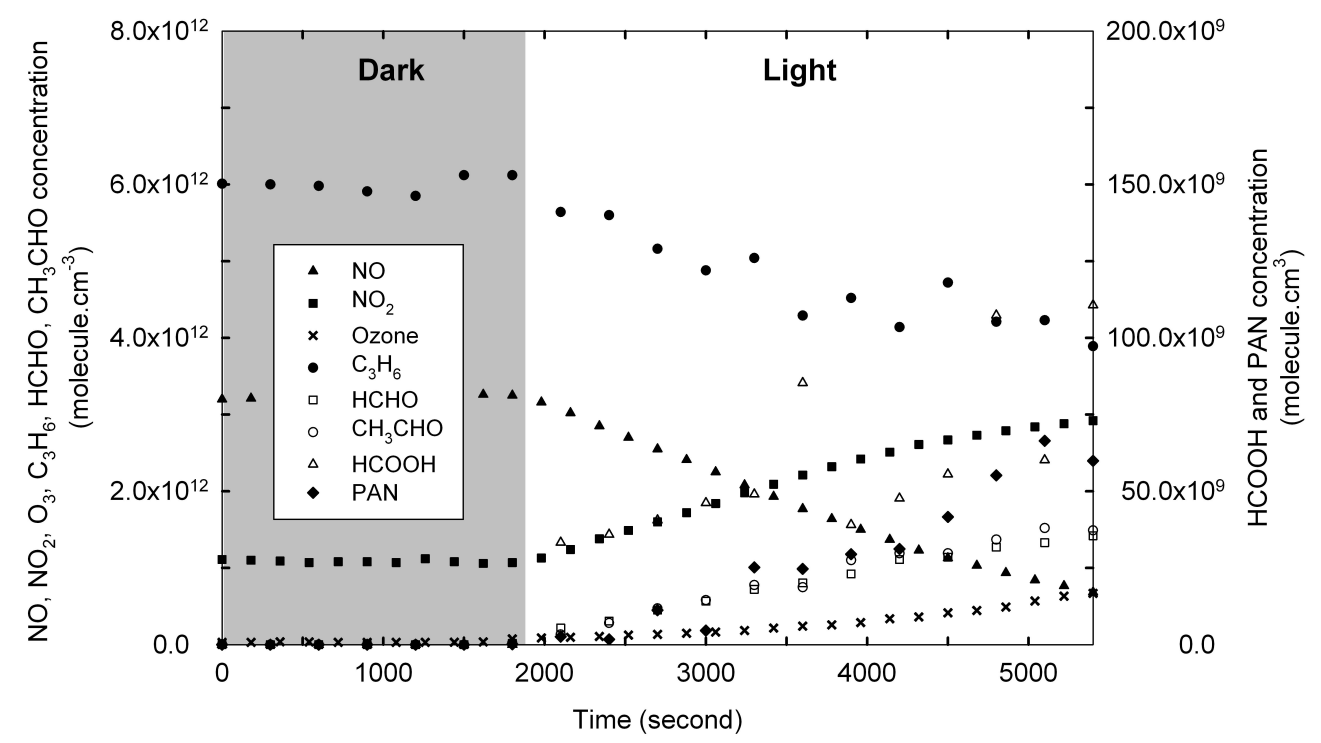

Fig. 7. Concentration-time profiles of $\mathrm{NO}_{\mathrm{x}}$, ozone, propene, $\mathrm{HCHO}, \mathrm{HCOOH}, \mathrm{CH}_{3} \mathrm{CHO}$, and $\mathrm{PAN}$ in a $\mathrm{C}_{3} \mathrm{H}_{6}-\mathrm{NO}_{\mathrm{x}}-\mathrm{Air}$ system.

heterogeneous effects is well recognized since the early times of the use of chambers (Grosjean, 1985), there is a paucity of data regarding the loss rates of organic and inorganic pollutants in environmental chambers. Moreover, McMurry and Grosjean (1985) have pointed out that wall losses could affect the secondary aerosol yield either by being a consumption pathway for SOA precursors in competition with oxidation or by being an additional sink for semi-volatile products preventing them from condensing on the aerosol phase. More recently, these artifacts have received a renewed interest by Matsunaga and Ziemann (2010) and Loza et al. (2010) with the growing recognition of the importance of SOA.

It is, hence, of primary importance to perform a careful evaluation of their extent. This is often a function of the chemical nature of the species considered as the processes involved can vary from simple adsorption to condensation or even reactive uptake. It must be said here that these parameters are often highly dependent on the chamber history and can also vary with the operating conditions such as temperature or relative humidity. As a consequence, the quantification must be carried on a case-by-case basis and a relevant set of test experiments must be associated with each series of experiments for each type of studies. This is why, whenever possible; it is preferable to derive these parameters for reactants from a "dark period" prior the start of each experiment (see Fig. 7).

However, in order to better describe the behavior of the walls of our chamber and to provide the reader with their order of magnitude, pseudo-first order wall losses have been compiled in Table 5. All experiments have been done with initial concentration ranging from 50 to $500 \mathrm{ppbv}$. The related lifetimes fall generally in the range of hours to days, which is enough to minimize their effect on the studied chemistry and to allows modelers to take them into ac-
Table 5. Pseudo-first order rates for loss processes in CESAM.

\begin{tabular}{lll}
\hline Compounds & $\begin{array}{l}\text { First order wall } \\
\text { loss rate }\end{array}$ & Comments \\
\hline $\mathrm{NO}_{2}$ & See Sect. 4.4.1 & $\begin{array}{l}\text { Complex } \\
\text { mechanism }\end{array}$ \\
$\mathrm{NO}$ & $<10^{-7} \mathrm{~s}^{-1}$ & Chamber \\
Ozone & $3.4 \times 10^{-5} \mathrm{~s}^{-1}$ & $\begin{array}{l}\text { history } \\
\text { dependant }\end{array}$ \\
& & \\
Formaldehyde & $<10^{-5} \mathrm{~s}^{-1}$ & \\
$\alpha$-Pinene & $<10^{-6} \mathrm{~s}^{-1}$ & \\
Propene & $<10^{-6} \mathrm{~s}^{-1}$ & \\
Isoprene & $(1.0 \pm 0.5) \times 10^{-6} \mathrm{~s}^{-1}$ & \\
Indene & $(2.0 \pm 0.5) \times 10^{-6} \mathrm{~s}^{-1}$ & \\
Methyl-Styrene & $(3.0 \pm 0.5) \times 10^{-6} \mathrm{~s}^{-1}$ & \\
\hline
\end{tabular}

count without significantly decreasing the precision of the simulations.

Aside the uptake of $\mathrm{NO}_{2}$ (which is discussed above) and of ozone which are supposed to be reactive processes, for most of these losses only adsorption can be suspected as no products have been detected so far.

Data concerning the wall losses of hydrocarbons are scarce. To our best knowledge, our data can only be compared with the work of Grosjean (1985) and McMurry and Grosjean (1985). While their evaluation was performed in Teflon ${ }^{\circledR}$ film chamber, it compares well with the present results as they report upper limits for first order wall loss rate in the range of $<3-5 \times 10^{-6} \mathrm{~s}^{-1}$ (e.g. $<4.8 \times 10^{-6} \mathrm{~s}^{-1}$ for methylstyrene). For propene, Wu et al. (2006) have 

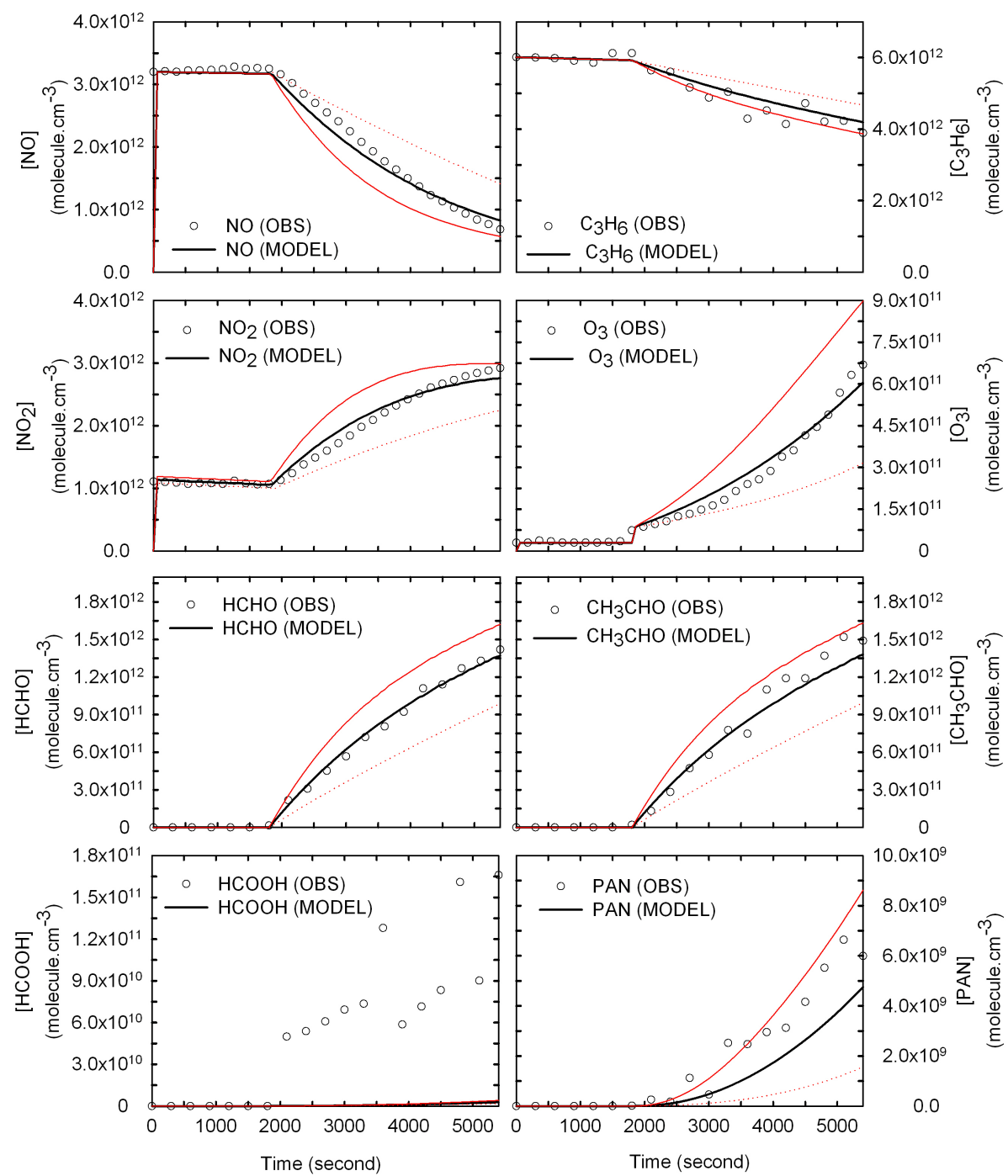

Fig. 8. Comparison of simulated (solid lines) and experimental concentrations (symbols) for $\mathrm{NO}, \mathrm{NO}_{2}$, ozone, propene, formaldehyde, acetaldehyde, formic acid and peroxyacetyl nitrate (PAN) in a propene- $\mathrm{NO}_{\mathrm{x}}$-Air system. Black lines are the results of modeling with an initial concentration of nitrous acid $[\mathrm{HONO}]_{0}=8 \mathrm{ppb}$ while continuous red lines are for $[\mathrm{HONO}]_{0}=12 \mathrm{ppb}$ and dashed red lines for $[\mathrm{HONO}]_{0}=4 \mathrm{ppb}$.

calculated a wall loss rate equal to $1.1 \times 10^{-7} \mathrm{~s}^{-1}$ for a Teflon film smog chamber of $2 \mathrm{~m}^{3}$ which is also compatible with the upper limit proposed here.

Due to its key role in the tropospheric chemistry, its chemical reactivity towards surfaces and its ubiquity in chamber experiments (as reactant or as product), ozone has always be the subject of a special attention with respect to wall reactions. A lot of data can be found in the literature and are reported in Table 6.

While an ozone loss equal to $3 \times 10^{-4} \mathrm{~s}^{-1}$ has been found for the specific experiment reported in Sect. 4.4.1, additional sets of experiments have shown that this value was dependent on the cleaning state of the walls. In particular, it was found that overnight treatment with ozone mixing ratio in the range of $100 \mathrm{ppm}$ followed by a secondary vacuum pumping was suitable to reach much longer ozone lifetime. Experiments during which $200 \mathrm{ppb}$ injected alone in the reactor were monitored as a function of time have led to lifetimes of $8 \mathrm{~h}$ corresponding to a $k_{\mathrm{O}_{3} \text { loss }}$ equal to $(3.4 \pm 0.3) \times 10^{-5} \mathrm{~s}^{-1}$. It was also found that after the passivation of the wall, overnight pumping alone allowed us to keep comparable $k_{\mathrm{O}_{3} \text { loss }}$ over several days. Similarly to Satthoff et al. (2009), this experiments have shown that passivating reactions can occur at the timescale of an experiment as the use of larger concentration of ozone ( $2 \mathrm{ppm})$ with the same procedure lead to much smaller ozone loss values, i.e. $(7.1 \pm 0.1) \times 10^{-7} \mathrm{~s}^{-1}$.

The value reported here are in good agreement with those reported in the literature (see Table 6). It can be observed that the choice of the chamber building material is clearly the dominant parameter as Teflon film chamber generally exhibit 
Table 6. Comparison for the dark ozone wall loss rate in chambers under dry conditions.

\begin{tabular}{|c|c|c|c|}
\hline Chamber & $\begin{array}{l}\text { Pseudo first } \\
\text { order ozone } \\
\text { loss }(s-1)\end{array}$ & Remarks & Reference \\
\hline $\begin{array}{l}\text { CESAM } \\
4.2 \mathrm{~m}^{3} \text { stainless steel chamber }\end{array}$ & $3.4 \times 10^{-5}$ & $\begin{array}{l}\text { Can be as low as } 3 \times 10^{-4} \mathrm{~s}^{-1} \\
\text { depending on chamber } \\
\text { history. }\end{array}$ & This work \\
\hline $\begin{array}{l}\text { NIES } \\
6.1 \mathrm{~m}^{3} \text { stainless steel chamber } \\
\text { coated with PFA }\end{array}$ & $3 \times 10^{-4}$ & After baking & Akimoto et al. (1979a) \\
\hline $\begin{array}{l}\text { NIES } \\
6.1 \mathrm{~m}^{3} \text { stainless steel chamber } \\
\text { coated with PFA }\end{array}$ & $1 \times 10^{-5}$ & After $\mathrm{O}_{3}$ treatment & Akimoto et al. (1979a) \\
\hline $\begin{array}{l}\text { AIDA } \\
90 \mathrm{~m}^{3} \text { indoor aluminium chamber }\end{array}$ & $3.9 \times 10^{-5}$ & $\begin{array}{l}\text { At } 303 \mathrm{~K} \text {, only } 5.2 \times 10^{-6} \mathrm{~s}^{-1} \\
\text { at } 243 \mathrm{~K}\end{array}$ & Saathoff et al. (2009) \\
\hline $\begin{array}{l}\text { SRI } \\
7.8 \mathrm{~m}^{3} \text { Teflon film chamber }\end{array}$ & $2.3 \times 10^{-5}$ & & Doyle (1970) \\
\hline $\begin{array}{l}\text { ERT Chamber } \\
3.9 \mathrm{~m}^{3} \text { outdoor Teflon film chamber }\end{array}$ & $5.6 \times 10^{-6}$ & $\begin{array}{l}\text { "Conditioned" by sunlight } \\
\text { irradiation and high } \mathrm{O}_{3} \\
\text { concentration }\end{array}$ & Grosjean (1985) \\
\hline $\begin{array}{l}\text { PSI } \\
27 \mathrm{~m}^{3} \text { indoor Teflon film chamber }\end{array}$ & $4 \times 10^{-6}$ & & Metzger et al. (2008) \\
\hline $\begin{array}{l}\text { Euphore } \\
200 \mathrm{~m}^{3} \text { outdoor Teflon film chamber }\end{array}$ & $3 \times 10^{-6}$ & & Bloss et al. (2005) \\
\hline $\begin{array}{l}\text { UCR EPA } \\
90 \mathrm{~m}^{3} \text { indoor Teflon film chamber }\end{array}$ & $2.2 \times 10^{-6}$ & & Carter (2003) \\
\hline $\begin{array}{l}\text { ERT Chamber } \\
60 \mathrm{~m}^{3} \text { outdoor Teflon film chamber }\end{array}$ & $2.1 \times 10^{-6}$ & $\begin{array}{l}\text { "Conditioned" by sunlight } \\
\text { irradiation and high } \\
\mathrm{O}_{3} \text { concentration }\end{array}$ & Grosjean (1985) \\
\hline $\begin{array}{l}\text { CSIRO } \\
18.1 \mathrm{~m}^{3} \text { aluminium chamber coated } \\
\text { with Teflon film }\end{array}$ & $1 \times 10^{-6}$ & After the first month of use & Hynes et al. (2005) \\
\hline $\begin{array}{l}\text { CSIRO } \\
18.1 \mathrm{~m}^{3} \text { aluminium chamber coated } \\
\text { with Teflon film }\end{array}$ & $2 \times 10^{-7}$ & After 3 years of use & Hynes et al. (2005) \\
\hline
\end{tabular}

a much better chemical inertia toward ozone than stainless steel or aluminum. From this data, it seems also that coating metal chambers may induce significant reduction of the chemical reactivity of the walls (see CSIRO results) but not always (see NIES). It is difficult to completely rationalize this comparison as many parameters such as the chamber history, the cleaning procedure but also the Teflon film supplier or the technology used to perform the coatings differs strongly from one facility to another. Again, regular monitoring of this key parameter from dedicated experiments combined with its determination during the experiments themselves thank to adapted procedure, whenever possible, are required for precise modeling of the ozone in simulation chamber as well as a for thoughtful characterization of the chemical state of the walls.

\subsubsection{Propene- $\mathrm{NO}_{\mathrm{x}}$ experiments}

A set of four propene- $\mathrm{NO}_{\mathrm{x}}$-air irradiation runs were carried out. This chemical system was chosen as the photo-oxidation of propene in smog chambers has been extensively investigated (Akimoto et al., 1979b; Akimoto and Sakamaki, 1983; Hatakeyama et al., 1991) and has been used as a reference system for chamber qualification tests (Carter et al., 2005; Hynes et al., 2005). 
The initial propene concentrations ranged from 140 to $600 \mathrm{ppb}$, and the propene $/ \mathrm{NO}_{\mathrm{x}}$ ratio from 0.6 to 2.3 . It should be pointed out that all runs were performed under dry conditions, with a controlled temperature at $298 \pm 3 \mathrm{~K}$, and at a pressure of $1008 \pm 5$ mbar. Figure 7 shows concentration-time profiles obtained from an irradiation of a propene/ $/ \mathrm{NO}_{\mathrm{x}} /$ air mixture experiments. A typical photosmog behavior can be observed from the experimental data. As mentioned earlier, the key compounds $\mathrm{NO}, \mathrm{NO}_{2}$ and ozone reach rapidly a photo-stationary state once the lights are turned on. The decrease of propene concentrations is due to the reactions of propene with ozone and $\mathrm{OH}$ radical, and leads to the production of secondary organic compounds, such as $\mathrm{HCHO}, \mathrm{CH}_{3} \mathrm{CHO}, \mathrm{HCOOH}$, and PAN (measured with FTIR).

To model all propene- $\mathrm{NO}_{\mathrm{x}}$ experiments, the Master Chemical Mechanism (MCM model v3 - Saunders et al., 2003) for propene was used. It was augmented with the auxiliary mechanism determined in the previous experiments of photooxidation of $\mathrm{NO}_{\mathrm{x}}$-air system.

The obtained mechanism comprises 263 reactions involving 69 chemical species. The temperature dependence of rate constants was taken into account in the model for all runs as well as the dilution due to sampling instruments.

The auxiliary mechanism was added without any tuning and the $\mathrm{NO}_{2}$ photolysis frequency was entered as determined in the $\mathrm{NO}_{\mathrm{x}}$-air system simulation section. Considering the realism of the spectral distribution of our light sources, the other photolysis frequencies used in the MCM were scaled from their atmospheric values using $J_{\mathrm{NO}_{2}}$ as a reference value. Only $[\mathrm{HONO}]_{0}$, the initial concentration of nitrous acid - was adjusted as HONO measurements were not available during the time of these experiments. It was necessary to vary this value in the range of $0-8 \mathrm{ppb}$ to correctly reproduce the oxidation rate and the initiation time. It was found that this value was roughly correlated with the time left between the injection of $\mathrm{NO}_{\mathrm{x}}$ and the start of the irradiation process which may be a sign of a minor reduction of $\mathrm{NO}_{\mathrm{x}}$ into HONO in the dark.

Figure 8 shows a comparison of experimental and simulated concentration-time profiles for a propene- $\mathrm{NO}_{\mathrm{x}}$-air experiment (others are provided as Supplement). An excellent agreement is obtained for most of the compounds i.e. $\mathrm{NO}_{\mathrm{x}}$, ozone, $\mathrm{HCHO}, \mathrm{CH}_{3} \mathrm{CHO}$, and PAN. Only formic acid shows large differences. The reason for this discrepancy is not clear. A trivial explanation could be a light-induced $\mathrm{HCOOH}$ offgassing from the wall at an average rate of $3 \mathrm{ppbh}^{-1}$. While such an off-gassing has not been detected in previous blank experiments carried out in the CESAM chamber, this hypothesis remains plausible as this specie is often in the background of chamber experiments. Nevertheless, this process was not added in the chemical scheme of the model because the benefit in term of additional understanding would have been low. Moreover, the sources of formic acid in the used chemical system are still subject of uncertainties. Indeed
Horie and Moortgat (1992) have proposed a series of reactions starting with the reversible addition of $\mathrm{HO}_{2}$ over $\mathrm{HCHO}$ which lead to formic acid. The formation rate of formic acid has been found to be highly dependent of the value of this equilibrium. However, this value is still a subject of controversy as only few studies have been carried out to determine its equilibrium constant (Su et al., 1979; Barnes et al., 1985; Veyret et al., 1989; Pinceloup et al., 2003; Jenkin et al., 2007). There is a general agreement on the value of the rate constant for direct reaction between $\mathrm{HO}_{2}$ and $\mathrm{HCHO}$. On the contrary, the range for the reverse pathway is much broader as it goes from $1.5 \mathrm{~s}^{-1}$ (Su et al., 1979) to $150 \mathrm{~s}^{-1}$ (Barnes et al., 1985; Veyret et al., 1989) which would lead to difference of two orders of magnitude for the $\mathrm{HCOOH}$ production in the CESAM chamber.

Despite the peculiar case of formic acid, it is remarkable that the use of the reaction set determined previously by modeling the sole photo-oxidation of $\mathrm{NO}_{\mathrm{x}}$-air system allows the modeling of photo-oxidation of propene- $\mathrm{NO}_{\mathrm{x}}$-air system. This tends to demonstrate that the wall reactivity affects mainly the $\mathrm{NO}_{\mathrm{y}}$ system and that the studies of unknown gas phase mechanism can be achieved providing that suitable control runs are performed.

Additional runs have been set up with an initial HONO concentration increased by $50 \%$ on one hand and decreased by $50 \%$, on the other hand. The results are shown on the Fig. 8. It shows that in the case of the chosen experiment, the initial HONO load is the main parameter which determines the propene oxidation rate. It is, remarkable to notice that combining its effect on the propene curves with those on NO, $\mathrm{NO}_{2}$ and ozone, this parameter is really sensitive and that there are little doubts on its value. These observations support strongly the need for precise nitrous measurement. Additional experiments are currently ongoing involving HONO monitoring to further investigate the chemical nature and the parameters affecting the nitrous acid off-gassing. They will be the subject of future publications.

The same model allowed us to investigate further the $\mathrm{HO}_{\mathrm{x}}$ chemistry in the CESAM chamber. Numerical tracers were introduced in the chemical code in order to evaluate the relative importance of various $\mathrm{OH}$ sources. In addition, tracers were also used to evaluate the relative importance of ozonolysis in the propene oxidation with respect to $\mathrm{OH}$ reaction. The results of these calculations for the experiment presented in Fig. 8 are given in Fig. 9.

These results show that the $\mathrm{OH}$ level is fairly stable around $3 \times 10^{6}$ radicals $\mathrm{cm}^{-3}$. Considering the value of the photolysis frequencies found for the CESAM chamber, this value is nicely comparable with the atmospheric levels (FinlaysonPitts and Pitts Jr., 2000).

The analysis of the various $\mathrm{OH}$ sources as traced by modeling shows the HONO photolysis is clearly the dominant source throughout the whole experiment. Nevertheless, at the end of the experiment when ozone concentration has reached a significant level, $\mathrm{O}^{1} \mathrm{D}$ reaction with water, and hence ozone 


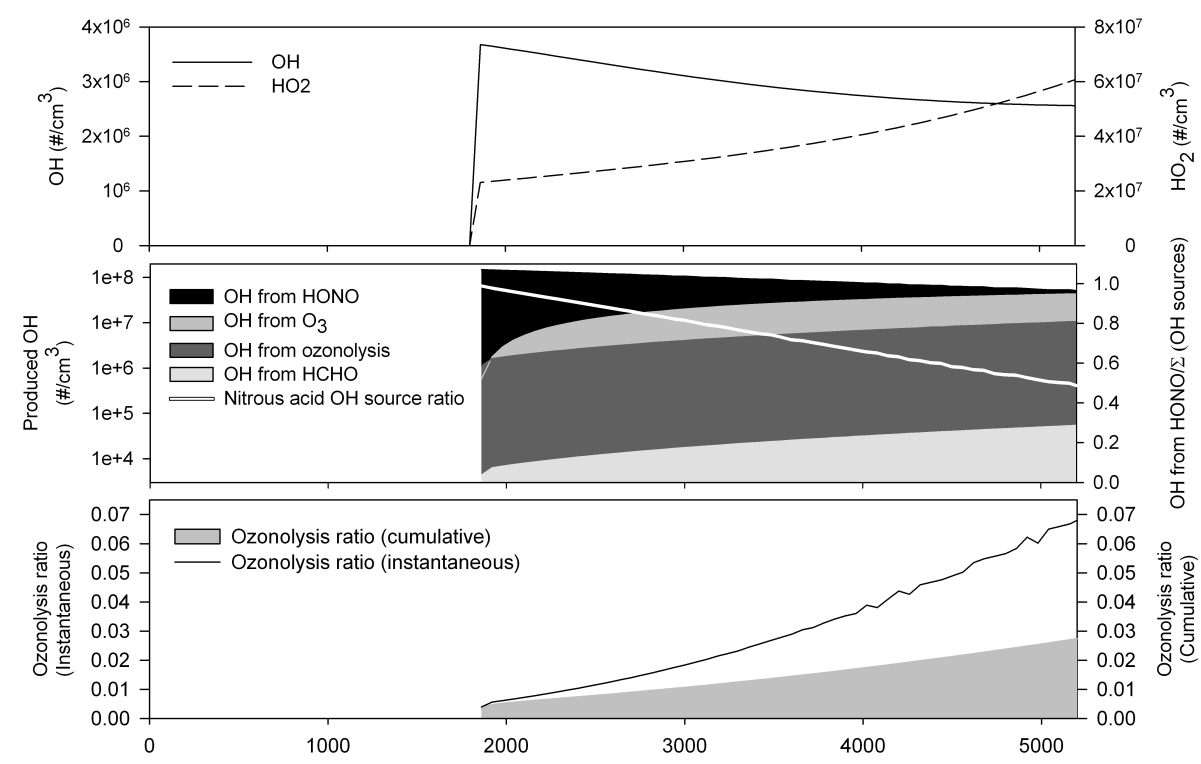

Fig. 9. Time dependent plot of the calculated $\mathrm{HO}_{\mathrm{x}}$ concentrations (top panel), the relative importance of $\mathrm{OH}$ sources (middle panel - areas are the instantaneous number of $\mathrm{OH}$ radical produced by each process while the white line is the relative importance of the HONO photolysis compared to other $\mathrm{OH}$ sources) and the relative importance of ozonolysis compared to $\mathrm{OH}$ radical initiated processes in the propene oxidation (lower panel - line is the instantaneous value while area is cumulative).

photolysis, becomes a nearly equivalent contributor: $47 \%$ of new $\mathrm{OH}$ are originating from $\mathrm{HONO}$ photolysis while $42 \%$ are from ozone photolysis. Similarly, at the end of the experiment, ozonolysis of propene contribute by $11 \%$ to the $\mathrm{OH}$ production. $\mathrm{OH}$ production from the photolysis of formaldehyde is always a quasi-negligible contributor.

These results are not surprising as ozone and formaldehyde can not represent significant $\mathrm{OH}$ precursors as they are not present in the initial mixture. It must be considered that these results are highly dependent on the experimental conditions. In particular, the relative contributions mentioned are highly depending on the HONO initial load which, for the experiment shown here, was in the higher range of the adjusted values. Because it affects the ozone concentration and $\mathrm{HONO}$ formation, the NO-to- $\mathrm{NO}_{2}$ ratio is also strongly affecting the distribution of the $\mathrm{OH}$ sources.

In addition, results about the ozonolysis extent show that this process is always of minor importance and represent, at the end, of the experiment less that $3 \%$ of the propene loss.

The modeling exercise described here can be seen as an illustration of the potential of the use of an explicit model such as the MCM to characterize the oxidant levels and sources during chamber runs.

\subsection{Aerosol behaviors}

\subsubsection{Aerosol particle background}

The chamber aerosol background has been tested by in situ monitors and a home-made nano-DMA coupled with our condensation particle counter (CPC) which can detect particles from $6 \mathrm{~nm}$ on. These tests have shown that no significant aerosol background was detected down to $6 \mathrm{~nm}$ diameter. In addition, the condensation particles counter (model 3010 from $\mathrm{TSI}^{\mathrm{TM}}$ ) was connected directly to the chamber during several experiments. This instrument used alone can detect particles from $3 \mathrm{~nm}$ to several micrometers diameter. This blank test leads routinely to the value of $25 \pm 5$ particles/cc in the background of the chamber demonstrating the efficiency of the cleaning procedure with respect to aerosol. Further measurements were carried out with the help of an Neutral Air Ion Spectrometer developed by AIREL Ltd. (Mirme et al., 2007) which have led to similar conclusion down to $2 \mathrm{~nm}$. In addition, as part of the routine blank protocol, aerosol background is checked by SMPS measurements (from 10 to $500 \mathrm{~nm}$ ) before each experiment.

Aside the reactor particle background itself, it was also very important to test whether there is species off-gassing from the walls which may affect the aerosol production during the irradiation or the oxidation of the studied reacting mixtures. This, of course, may depend on the chamber history, but one may report here that many non-forming aerosol systems have been studied within the time frame of several hours while no particle were detected from SMPS measurement. They includes photolysis of $\mathrm{NO}_{\mathrm{x}}$ alone in various $\mathrm{NO} / \mathrm{NO}_{2}$ ratio (some are reported in this paper), photolysis of light VOC such as propene or formaldehyde in the presence of $\mathrm{NO}_{\mathrm{x}}$ and under dry condition. The initial concentrations were ranging from $100 \mathrm{ppbv}$ to several ppmv. In none of these experiments, unexpected SOA formation was detected. 
Table 7. Initial conditions and results summary for the set of experiments $\alpha$-pinene $+\mathrm{O}_{3}$.

\begin{tabular}{lccrrrrr}
\hline $\begin{array}{l}\text { Experiment } \\
\text { number }\end{array}$ & $\begin{array}{c}\text { Temp. } \\
(\mathrm{K})\end{array}$ & $\begin{array}{r}\mathrm{RH} \\
(\%)\end{array}$ & $\begin{array}{r}\mathrm{O}_{3_{\text {initial }}} \mathrm{ppbv} \\
100323-\mathrm{B}\end{array} 295 \pm 0.5$ & $\begin{array}{r}\mathrm{HC}_{\text {initial }} \\
\mathrm{ppbv}\end{array}$ & $\begin{array}{r}\Delta \mathrm{HC} \\
\mu \mathrm{g} \mathrm{cm}^{-3}\end{array}$ & $\begin{array}{r}\Delta M_{\mathrm{O}} \\
\mu \mathrm{g} \mathrm{cm}^{-3}\end{array}$ & $\begin{array}{r}\text { SOA } \\
\text { Yield }\end{array}$ \\
\hline $100323-\mathrm{C}$ & $295 \pm 0.5$ & $<1 \%$ & 100 & 29.7 & 160.0 & 19.5 & 0.121 \\
$100323-\mathrm{A}$ & $295 \pm 0.5$ & $<1 \%$ & 180 & 79.1 & 410.7 & 64.1 & 0.156 \\
$100320-\mathrm{B}$ & $295 \pm 0.5$ & $<1 \%$ & 900 & 82.3 & 548.7 & 95.8 & 0.174 \\
$100322-\mathrm{A}$ & $294 \pm 0.5$ & $<1 \%$ & 200 & 149.0 & 750.2 & 140.9 & 0.188 \\
$100322-\mathrm{B}$ & $295 \pm 0.5$ & $<1 \%$ & 400 & 269.0 & 1428.2 & 384.5 & 0.269 \\
$100320-\mathrm{A}$ & $295 \pm 0.5$ & $<1 \%$ & 1150 & 205.5 & 1149.4 & 324.6 & 0.282 \\
\hline
\end{tabular}

Additional dedicated experiments involving the photolysis of $\mathrm{NO}_{\mathrm{x}}$ (ca. $200 \mathrm{ppbV}$ ) in the presence of ammonium sulfate seeds have been carried out. The initial aerosol loading has been kept low (ca. $3 \mu \mathrm{g} \mathrm{m}^{-3}$ ) in order to have a sufficiently low relative uncertainty, so to detect a possible SOA production close to the detection limit values. No SOA production was detected for irradiation period in the range of five hours.

Considering the uncertainties associated with the dilution rate measurements and the noise in the SMPS measurement, an upper limit for background SOA production can be estimated around $<0.01 \mu \mathrm{g} \mathrm{m}^{-3}$.

\subsubsection{Aerosol generation}

Several procedures can be used to produce aerosols in CESAM.

Sub-micrometer aerosols can be generated from a salt solution and injected into the chamber by using a commercial constant output Atomizer (TSI Inc., model 3076). The mean particle size of the generated aerosol can be varied between 0.03 and $0.3 \mu \mathrm{m}$ by atomizing the adequate solution and evaporating the remaining water, with the help of a commercial aerosol drier (TSI Inc., model 3062). As shown in Fig. 10, by atomizing a solution of $0.03 \mathrm{moll}^{-1}$ of $\left(\mathrm{NH}_{4}\right)_{2} \mathrm{SO}_{4}$ and $0.05 \mathrm{moll}^{-1}$ of $\mathrm{H}_{2} \mathrm{SO}_{4}$ with a flow rate of $0.21 \mathrm{~min}^{-1}$ for $10 \mathrm{~min}$, one can produce an aerosol exhibiting a median size of $50 \mathrm{~nm}$ within a few minutes after the injection into the chamber that will slowly grow up to $100 \mathrm{~nm}$ with a concentration of about $270 \mu \mathrm{g} \mathrm{m}^{-3}$. A quite broad size distribution is obtained (Fig. 10). By using a Differential Mobility Analyzer to select one particle size, one can produce a monodisperse aerosol as described by De Haan et al. (1999). In this case, the process of monodisperse particle selection may slow down the whole particle injection to the chamber.

Aside the production of water soluble inorganic particles, the generation of secondary organic aerosols was also investigated. This last type of process is of importance for the improvement of chemistry-transport atmospheric models (Kanakidou et al., 2005) and has received the most attention from the scientific community. As a consequence, it was of primary importance to check if any chamber depen-

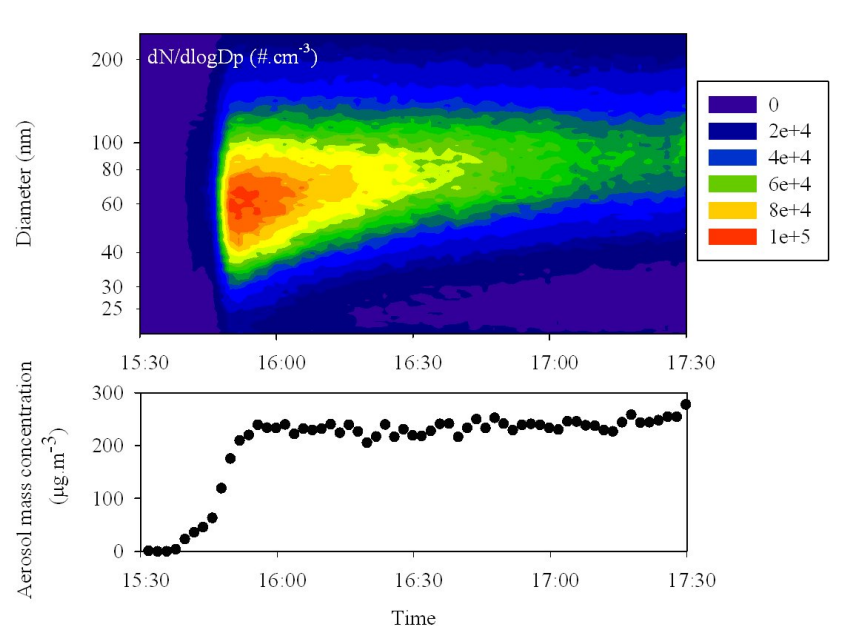

Fig. 10. Time dependent plot of the behavior of ammonium sulfate particles $\left(\left(\mathrm{NH}_{4}\right)_{2} \mathrm{SO}_{4}\right)$ injected in CESAM chamber. Top panel: aerosol size distribution in number as measured with SMPS; bottom panel: aerosol mass concentration derived from SMPS measurement assuming a density of $1.77 \mathrm{~g} \mathrm{~cm}^{-3}$ for $\left(\mathrm{NH}_{4}\right)_{2} \mathrm{SO}_{4}$.

dent artifact could affect the dynamic of these processes and the overall aerosol yields obtained. To do so, the ozonolysis of $\alpha$-pinene was chosen as a reference system. Indeed, this reaction is certainly the one which has received the more attention with respect to SOA formation and hence for which numerous data can be found in the literature (Hoffmann et al., 1997; Griffin et al., 1999; Cocker III et al., 2001b; Saathoff et al., 2009). Furthermore, in contrast with other chemical systems, the ozonolysis of $\alpha$-pinene leads to aerosol yields which are only weakly dependent on the presence or absence of seed particles and on the chemical nature of these seeds (Pathak et al., 2007). A set of experiments was carried out under dry conditions, in the dark, at ambient temperature (i.e. $295 \pm 2 \mathrm{~K}$ ) and in the absence of $\mathrm{OH}$ scavenger. Seven experiments were carried out with initial precursor mixing ratios ranging from 29 to $269 \mathrm{ppb}$ (see Table 7).

Aerosol production was monitored using a SMPS, the data from which were cross-checked with the help of a Tapered Element Oscillating Microbalance (TEOM, 


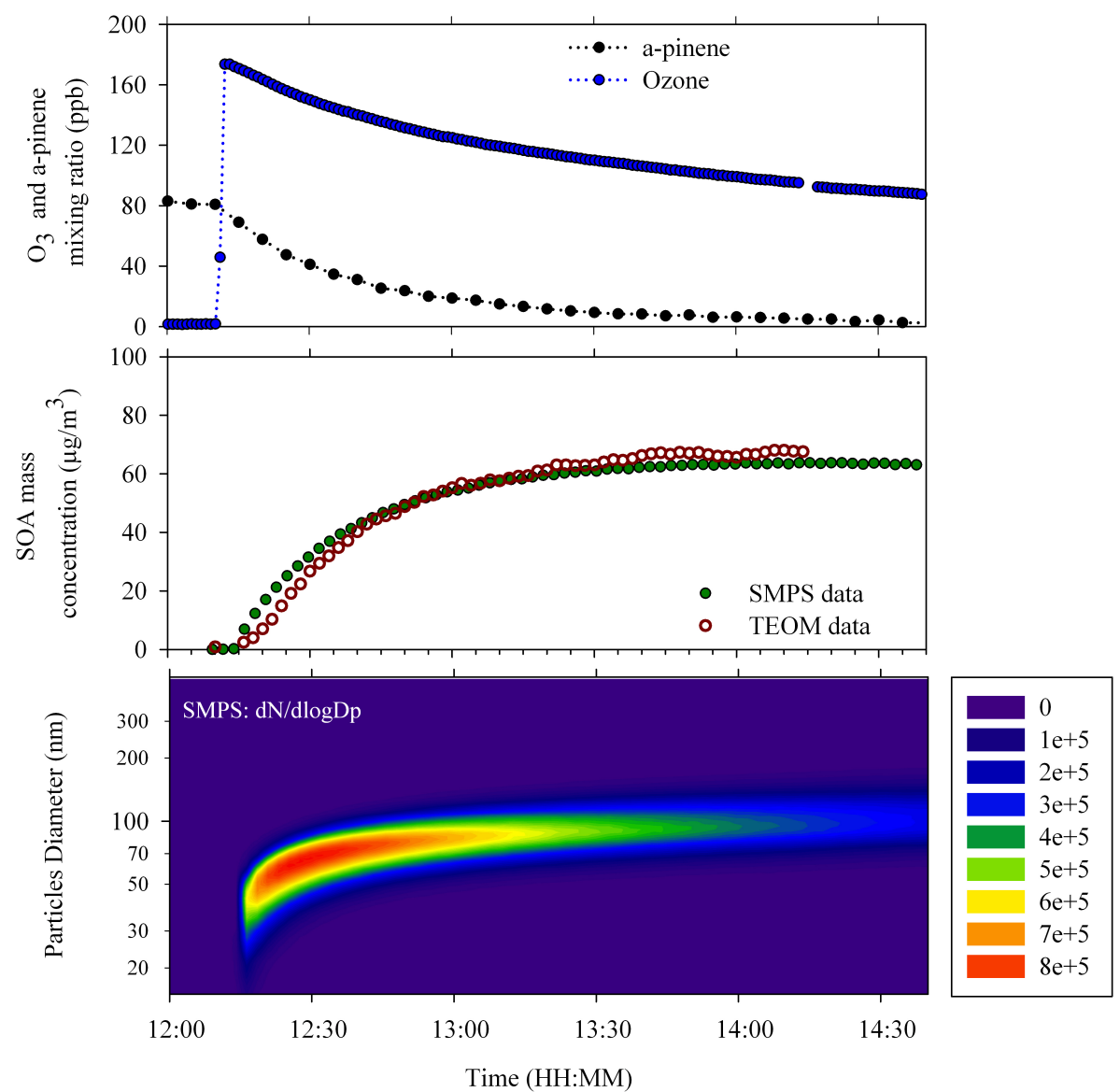

Fig. 11. Time dependent concentrations, aerosol mass and size distribution during an experiment of ozonolysis of $\alpha$-pinene (experiment \#100323-A). Top panel: ozone and $\alpha$-pinene concentrations from ozone monitor and FTIR measurements; middle panel: aerosol mass concentrations from both SMPS and TEOM measurements; bottom panel: aerosol size distribution in number determined by SMPS.

Rupprecht \& Patashnick ${ }^{\circledR}$ ) maintained at 300 K. All the concentrations were precisely corrected from dilution thanks to the monitoring of the flow rate of nitrogen introduced, through a regulated mass flow controller $\left(\mathrm{MKS}^{\circledR}\right)$. This MFC was computer-programmed to maintain the chamber pressure at 1020 mbar. The dilution rate was varying with the number and the type of instruments used in the range of $2 \times 10^{-5} \mathrm{~s}^{-1}$.

As it can be seen in Fig. 11, the TEOM and SMPS data follow nicely the same tendency when a density of $1 \mathrm{~g} \mathrm{~cm}^{-3}$ is used to convert the volume concentration data into mass concentration. This result is somewhat in contradiction with the data from Chan et al. (2009) or Saathoff et al. (2009) who proposed a value of $1.25 \pm 0.1 \mathrm{~g} \mathrm{~cm}^{-3}$ on the basis of data combining SMPS and AMS measurements. On the contrary, Wirtz and Martin-Reviejo (2003), using the same combination of instruments as the one used in this work, have determined a value of $1.04 \pm 0.09 \mathrm{~g} \mathrm{~cm}^{-3}$. In consequence a density of 1.0 was kept for the whole set of experiments. Indeed, the TEOM was not always used as its sampling rate may have led to increased uncertainty due to additional dilution correction.
In order to compare the SOA production in the CESAM chamber with the literature data, the aerosol yield concept was used. This yield $Y$ is defined as follows

$$
Y=\frac{M_{\mathrm{o}}}{\Delta \mathrm{VOC}}
$$

where $M_{\mathrm{O}}$ is the organic aerosol mass concentration (in $\mu \mathrm{g} \mathrm{m}^{-3}$ ) at the end of the reaction while $\triangle \mathrm{VOC}$ is the mass concentration variation of the precursor (in $\mu \mathrm{g} \mathrm{m}^{-3}$ ). As these yields exhibit a non linear behavior with reaction advancement due to phase exchanges, their formalization has been achieved considering the phase partitioning of SOA components (Pankow, 1994; Odum et al., 1996). The basis of this theory is that SOA comprises a mixture of semi-volatile organic compounds that partition between the gas and particle phases. Partitioning for a given species $i$ is described by an equilibrium partitioning coefficient $K_{P, i}\left(\mathrm{~m}^{3} \mathrm{\mu g}^{-1}\right)$,

$K_{P, i}=\frac{P_{i}}{G_{i} M}$

where $P_{i}$ and $G_{i}$ are respectively the mass concentration in the particulate phase and in the gas phase and $M$ the total aerosol mass concentration. If one introduces $\alpha_{i}$ as the 


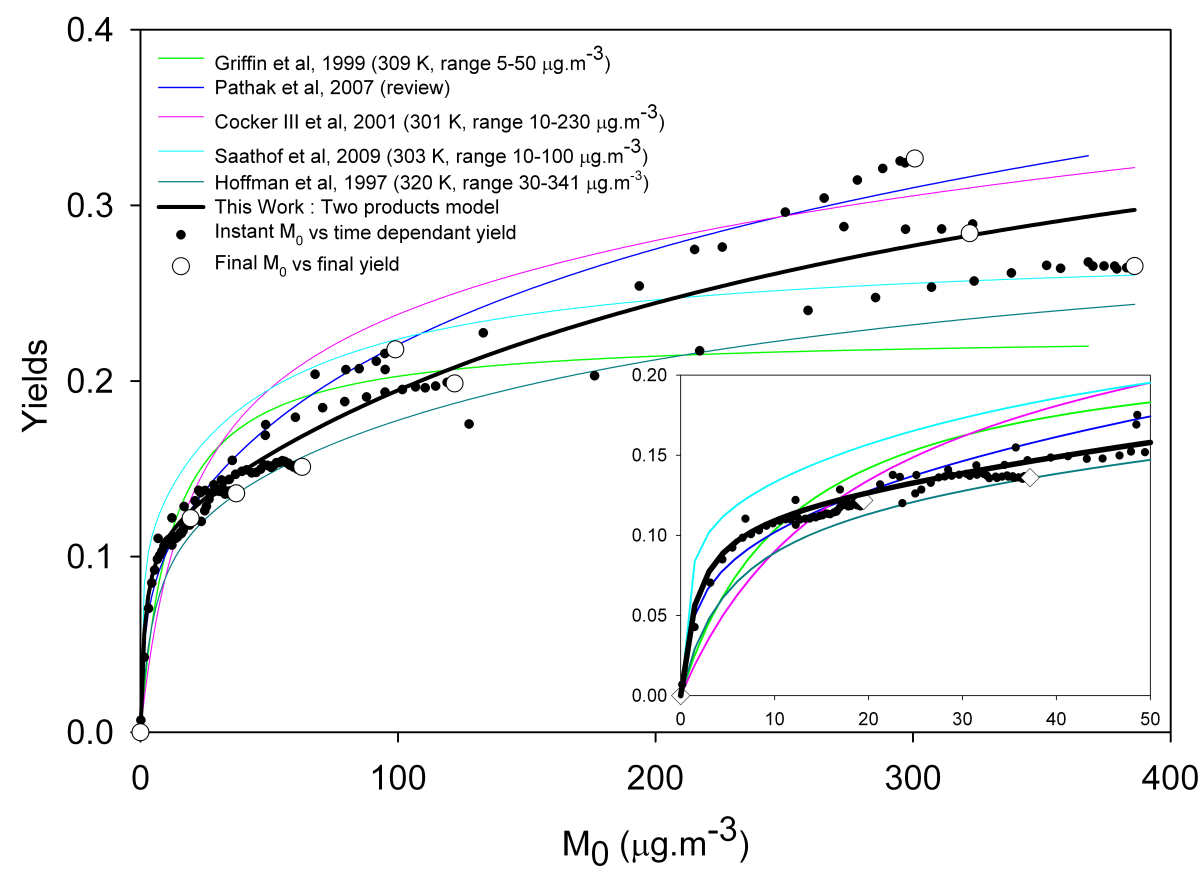

Fig. 12. Comparison of yield obtained in this work (Table 7) with the two-product models obtained from other studies for the dry and dark ozonolysis of $\alpha$-pinene. Note: the relation proposed by Pathak et al. (2007) is based on the VBS approach.

stoechiometric coefficient for the production of species $i$, it comes the following equation:

$Y=\sum Y_{i}=M_{\mathrm{o}} \sum \frac{\alpha_{i} \cdot K_{P, i}}{1+M_{\mathrm{o}} \cdot K_{P, i}}$.

Odum et al. (1996) have shown that two products were enough to allow Eq. (3) to fit their data within the experimental errors. As a result, the two-products model has been used as the most common way for parameterizing SOA data in many experimental and modeling studies (Seinfeld et al., 2003; Kanakidou et al., 2005; Hallquist et al., 2009). For chamber data, the "two-products model" has became the standard mean of representing SOA yield data while, it has been shown that this type of parameterization does not always give a unique representation (Pathak et al., 2007). In this work we have adopted the two-products approach in order to compare our data with other similar studies. It comes as

$Y=M_{\mathrm{o}} \cdot\left(\frac{\alpha_{1} \cdot K_{P, 1}}{1+M_{\mathrm{o}} \cdot K_{P, 1}}+\frac{\alpha_{2} \cdot K_{P, 2}}{1+M_{\mathrm{o}} \cdot K_{P, 2}}\right)$

Figure 12 shows our experimental data together with the data published for similar studies. Only the yields obtained for the dark ozonolysis of $\alpha$-pinene, near $300 \mathrm{~K}$, under dry conditions and without the use of any $\mathrm{OH}$-scavenger were considered.

It can be seen from this plot that our results fall nicely in the range of results of previous studies. Only the data of Saathoff et al. (2009) in the low aerosol mass loading range and the data of Cocker III et al. (2001b) significantly differ from our results. It must be noticed that the slight dispersion of our data in the low yield range is probably due to lack of sensibility of the FTIR analysis for $\alpha$-pinene. Nevertheless, when one compares our results to other chamber studies, it seems clear that no significant chamber artifact affecting the SOA production in CESAM can be detected from this work.

The $\alpha$ and $K_{P}$ parameters obtained from the fit of our data with Eq. (4) are given in Table 8 together with those found in the literature. It can be seen that they fall in the same range while a significant discrepancy remains between these sets of parameters. This fact illustrates quite well the limit of this approach. It can be also noticed that our parameters are in fair agreement with the parameters proposed by Hoffmann et al. (1997) for the volatile component (product 2). For the lower mass loadings $\left(<10 \mu \mathrm{g} \mathrm{m}^{-3}\right)$ which are most relevant to atmospheric conditions, the parameterization that we propose is in good agreement with the one proposed in the review of Pathak et al. (2007).

\subsubsection{Particle lifetime}

Numerous studies have shown that major chemical transformations of the particles occur after several hours of reaction (Seinfeld and Pankow, 2003; Baltensperger et al., 2005; Kalberer et al., 2006). As an example, Kalberer et al. (2006) have shown that high molecular weight species can be detected thanks to aerosol mass spectrometry only after six hours of reaction. Another example taken from Seinfeld 
Table 8. Comparisons of the two-product equation parameters obtain from this work and proposed in the literature for comparable study.

\begin{tabular}{lllllll}
\hline Reference & $\begin{array}{l}M_{\mathrm{O}} \\
\text { range } \\
\mu \mathrm{g} \mathrm{m}^{-3}\end{array}$ & $\begin{array}{l}\text { Temp. } \\
\end{array}$ & $\alpha_{1}$. & $K_{\mathrm{P} .1}$ & $\alpha_{1}$ & $K_{\mathrm{P} .2}$ \\
\hline This work & $20-370$ & $295 \pm 0.5$ & $0.11 \pm 0.01$ & $0.40 \pm 0.16$ & $0.29 \pm 0.02$ & $0.004 \pm 0.001$ \\
Hoffmann et al. (1997) & $2-100$ & 320 & 0.12 & 0.2 & 0.19 & 0.005 \\
Griffin et al. (1999) & $5-50$ & 309 & 0.125 & 0.088 & 0.102 & 0.0788 \\
Cocker III et al. (2001b) & $10-203$ & 301 & 0.239 & 0.056 & 0.220 & 0.0019 \\
Saathoff et al. (2009) & $10-100$ & 303 & 0.11 & 1.67 & 0.169 & 0.021 \\
\hline
\end{tabular}

and Pankow (2003), shows that the hygroscopic properties of an organic aerosol produced from the photo-oxidation of $\alpha$-pinene tends to change significantly in the hours following its production in smog chamber (Seinfeld and Pankow, 2003). In short, there is growing evidence that it is necessary to be able to maintain a significant quantity of aerosols in suspension for a sufficient time to address the chemical transformation of particles and their impacts on aerosol properties during atmospheric transport. Unfortunately, in most simulation chambers, wall deposition often limits their residence time. One of the main driving forces for the chamber particles loss is due to diffusion and mixing processes, but also in many case electrostatic drawing.

The characterization of the CESAM chamber has involved particle lifetime experiments. As shown in Fig. 8, the secondary particles are generated by the ozonolysis of $100 \mathrm{ppb}$ of sabinene. Ozonolysis of sabinene was chosen as there is a significant expertise in our group with this chemical system (Chiappini et al., 2006). In these experiments, ozone produced from a discharge generator is injected first, and then sabinene is introduced to the chamber. After few seconds, a monomodal distribution is detected with the SMPS (see Fig. 13). All along the experiment, the mixing fan is kept on. The particle lifetime is determined assuming first-order decay i.e. by adjusting a simple exponential decay to the experimental data in mass concentration taken after the end of SOA formation. For the experiment shown in Fig. 13, the particle lifetime is calculated once the SOA mean mass concentration becomes stable at $60 \mu \mathrm{g} \mathrm{m}^{-3}$, with a particle size distribution centered at $50 \mathrm{~nm}$.

From the results of all experiments carried out in CESAM, particle lifetime can vary from $10 \mathrm{~h}$ to 4 days depending on the particle size distribution and the cleanliness of the chamber. Results show that CESAM chamber provides a long particle lifetime which compares well with the atmospheric particle lifetime of 1 to 3 days proposed by Williams et al. (2002) for particles ranging from $20 \mathrm{~nm}$ to $5 \mu \mathrm{m}$ in the boundary layer. This feature will be of valuable interest to investigate atmospheric aerosol chemical aging. As shown in Table 9, this aerosol lifetime falls in the same range as those obtained for much larger chambers (i.e. from 5 to 50 times
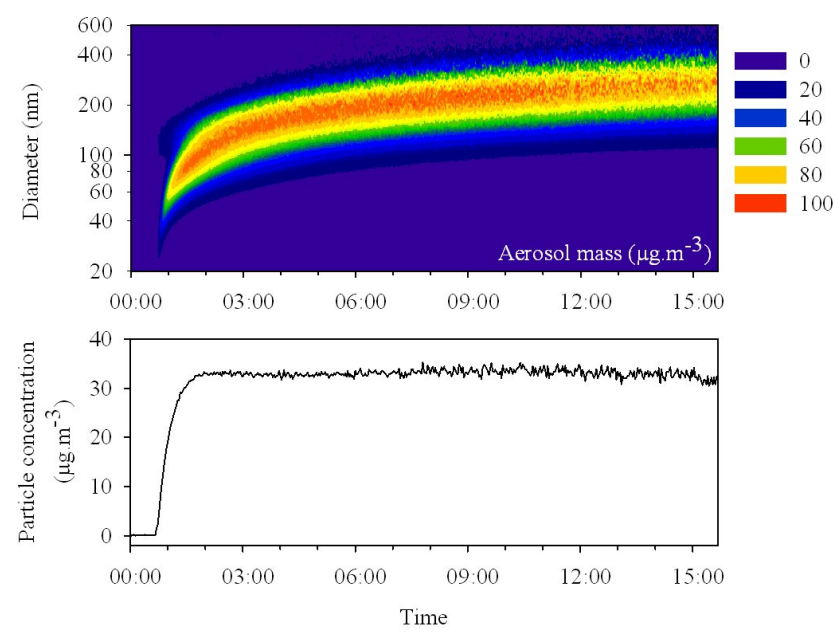

Fig. 13. Aerosol lifetime experiment. Aerosol mass concentration and aerosol size distribution in mass during an aerosol production experiment from the ozonolysis of $100 \mathrm{ppb}$ of sabinene. Top panel: aerosol size distribution in mass as measured with SMPS; bottom panel: aerosol mass concentration derived from SMPS measurement assuming a density of $1 \mathrm{~g} \mathrm{~cm}^{-3}$.

larger). Unfortunately, no comparison can be made with smaller simulation chamber as it was not possible to get this information from our literature search.

Attempt to apply the approach proposed by Crump et al. (1983) for monodisperse aerosol in steady state reactor to polydisperse aerosol experiments in CESAM has been made. Following the general theory of Crump and Seinfeld (1981), the dilution term, the wall loss and the coagulation term were calculated and theoretical number concentration curves as a function of time were compared to the experimental one. Experimentally-determined and calculated number concentrations were found in good agreement when taking, after correction from the chamber radius, the parameters calculated by McMurry and Rader (1985) for experimental condition without any electrostatic drowning. This approach has shown that aerosol loss parameter $(\beta)$ falls in the range of few $10^{-6} \mathrm{~s}^{-1}$ or better and helps in rationalizing the very low aerosol loss observed when mass concentration as a function 
Table 9. Comparison of aerosol lifetime in different aerosol chamber facilities.

\begin{tabular}{|c|c|c|c|c|}
\hline Chamber facility & $\begin{array}{r}\text { Volume } \\
\qquad\left(\mathrm{m}^{3}\right)\end{array}$ & $\begin{array}{l}S / V \\
\left(\mathrm{~m}^{-1}\right)\end{array}$ & $\begin{array}{l}\text { Wall } \\
\text { material }\end{array}$ & $\begin{array}{l}\text { Aerosol } \\
\text { lifetime }\end{array}$ \\
\hline CESAM (FR) & 4.2 & 4.29 & $\begin{array}{l}\text { Stainless } \\
\text { steel }\end{array}$ & $\begin{array}{l}\text { up to } \\
4 \text { days }\end{array}$ \\
\hline AIDA $(\text { GER })^{\mathrm{d}}$ & 78 & 1.30 & $\mathrm{AlMg}_{3}$ & 5 days \\
\hline Tsinghua (China) $)^{\mathrm{e}}$ & 2 & 4 & Teflon & $<14 \mathrm{~h}$ \\
\hline Caltech (US) ${ }^{\mathrm{c}}$ & 28 & 1.99 & Teflon & $74 \mathrm{~h}$ \\
\hline $\mathrm{UCR}(\mathrm{US})^{\mathrm{b}}$ & 90 & 1.53 & Teflon & 7 days \\
\hline Jülich $(\text { GER })^{\mathrm{a}}$ & 260 & $<1$ & Teflon & $\begin{array}{l}\text { More than } \\
48 \mathrm{~h}\end{array}$ \\
\hline
\end{tabular}

${ }^{\text {a }}$ Maso et al. (2007), ${ }^{\mathrm{b}}$ Carter et al. (2005), ${ }^{\mathrm{c}}$ Cocker et al. (2001a), ${ }^{\mathrm{d}}$ Wagner et al. (2006), ${ }^{\mathrm{e}}$ Wu et al. (2006)

of time are considered. As examples, one can compare with the aerosol loss reported by Wu et al. (2006) which ranges around $2 \times 10^{-5} \mathrm{~s}^{-1}$ for a $2 \mathrm{~m}^{3}$ Teflon film chamber or with the $\beta$ value measured at $(2-5) \times 10^{-5} \mathrm{~s}^{-1}$ reported by Cocker et al. (2001a) in a $28 \mathrm{~m}^{3}$ Teflon film chamber. It can be hypothesized here that the fact that the body of our chamber is made of a conductive, and electrically-grounded, material is certainly a parameter which keep at very low level the accumulation of electrostatic charges. Electrostatic forces can probably be neglected when the aerosol physical behavior is being investigated. Nevertheless, in our case, these calculations are not without any approximation in the input parameters, this is why it must be considered only as an upper limit and why aerosol dynamic simulations have still to be performed. These will be the subject of a further study.

\subsection{Cloud generation}

As discussed previously, the CESAM chamber was designed and constructed as a multiple use facility for both atmospheric gas-phase chemistry investigation and aerosol research. In the domain of atmospheric chemistry, it is well known that precipitations can play an important role in aerosol global cycle by wet scavenging processes which depend on large-scale features such as cloud formation, conversion of clouds into rain drops, sedimentation and evaporation of rain droplets (Kanakidou et al., 2005). Besides, wet-scavenging is also largely affected by the microphysical properties of the aerosols which are still poorly parameterized as a function of mixing state, chemical composition or chemical history. In return, concerning aerosols, the processes involved in aerosol aging during and after the cloud formation are still not known. Indeed, it has been shown that in-cloud oxidation of an organic compound may lead to the increase of aerosol mass (Lim and Ziemann, 2005; Ervens et al., 2008; De Haan et al., 2009) and that in-cloud processing of already existing aerosol may lead to an important change of their size distribution (Hatzianastassiou et al., 1998), their optical properties (Hatzianastassiou et al., 1998; Hegg et al., 2004) or their ability to act as a condensation cloud nuclei (Bower et al., 1997; Choularton et al., 1998; Crumeyrolle et al., 2008).

As a consequence, the ability for a simulation chamber to allow generation of a cloud (or fog) is an important feature to address the relationship between air mass conditions encountered by an aerosol during its atmospheric transport and its chemical composition or its properties. While a number of infrastructures have been designed to study cloud microphysics (Hobbs, 1993; Pruppacher and Klett, 1997; Stratmann et al., 2004), only few chambers, e.g. the AIDA chamber (Wagner et al., 2006), the UMR cloud simulation chamber (Hagen et al., 1989), the Calspan environmental chamber (Hoppel et al., 1994), and the CSU isothermal cloud chamber (Steele et al., 1970), have offered the possibility to study on a chemical point of view the effect of cloud formation on aerosols. Considering the design of CESAM which makes it an evacuable chamber equipped with double shell wall (cooling system is still under development), it was important to test the possibility to produce sufficiently stable cloud/fog under well defined conditions to allow reproducibility.

To do so, two different procedures have been tested: one is based on the fast expansion of a close-to-saturation synthetic air/water gaseous mixture and the second is based on the progressive saturation of synthetic air by adding water vapor to the reactor.

While these procedures have been tested and used several times in our lab, a specific experiment has been performed which combines these two procedures for demonstrating purpose and is shown in Fig. 14.

Water vapor is produced in a small pressurize stainless steel vessel which is located below the chamber and directly connected to it. It is filled with ultrapure water (18.2 M $\Omega$, ELGA Maxima) and heated until the pressure reaches 1500 mbar. This small reactor is purged at least five times from any residual air prior injection in the chamber. Injection inside CESAM is performed through $1 / 4$ inch stainless steel heated tubing by using a port located just below the fan to allow a fast mixing and minimize any significant condensation. Injection time is the parameter used to adjust the relative humidity and a needle valve is operated to control the vapor flux allowed to the chamber.

To provide an in situ detection of the cloud formation, a simple device has been set up by using a $632 \mathrm{~nm}$ laser beam $(\mathrm{He}-\mathrm{Ne}$ ) and a photodiode (BS520) which are mounted at $2 \mathrm{~m}$ distance from each other on two opposite flanges. The diode is located slightly out of the laser beam. Hence, no signal is received from the direct light emitted from the laser and only the signal scattered by the cloud droplets can be detected. Such geometry allows detection at very small scattering angle which offers a nice sensitivity. Mie Calculations performed using the MiePlot v4.0 software (Laven, 2003) shows that such an arrangement offers an increasing sensitivity with 

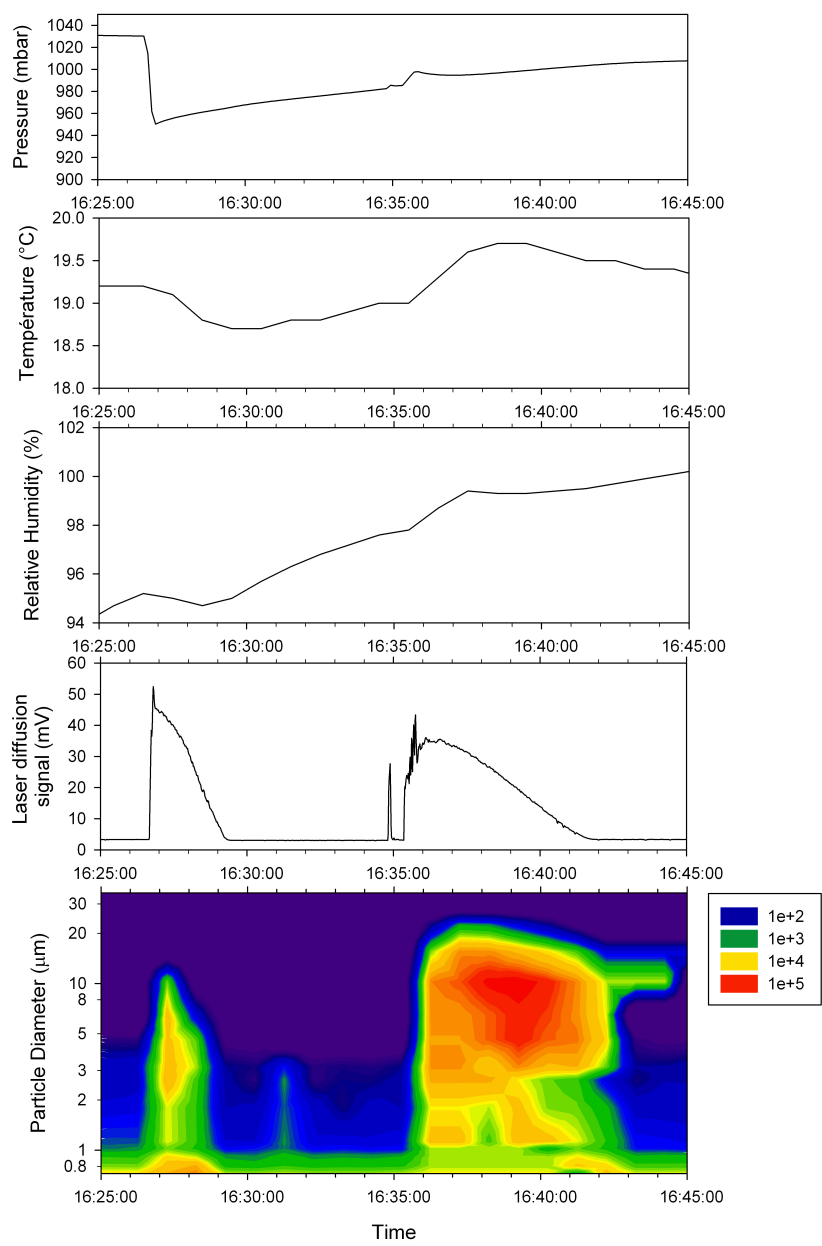

Fig. 14. Cloud generation experiments. Two cloud events are generated: the first from fast expansion and the second by progressive saturation. Panels from top to bottom: pressure, temperature and relative humidity in the CESAM chamber, laser diffusion signal and aerosol mass concentration derived from Grimm ${ }^{\mathrm{TM}}$ Aerosol Spectrometer measurement assuming a refractive index of $1.33-0.0 \times i$.

an increasing size of droplets. In consequence the received scattering signal is a convolution of the effects of both the number and size of droplets.

To gain information on the full size distribution, a Grimm ${ }^{\circledR} 1.108$ Aerosol Spectrometer (Grimm Aerosol Technik GmbH \& Co., Ainring, Germany) was connected to the chamber. As this optical counter has not been designed for the determination of water droplet size distribution but rather for aerosol measurement purposes, and because its calibration is performed using polystyrene latex (PSL) beads, it was necessary to correct its response factor to take into account differences induced by differing refractive indices. To do so, the calculated light scattering intensity by PSL particles of diameters corresponding to Grimm ${ }^{\circledR}$ mid-bin size (exhibiting a complex refractive index equal to $1.59-0.0 \mathrm{i}$

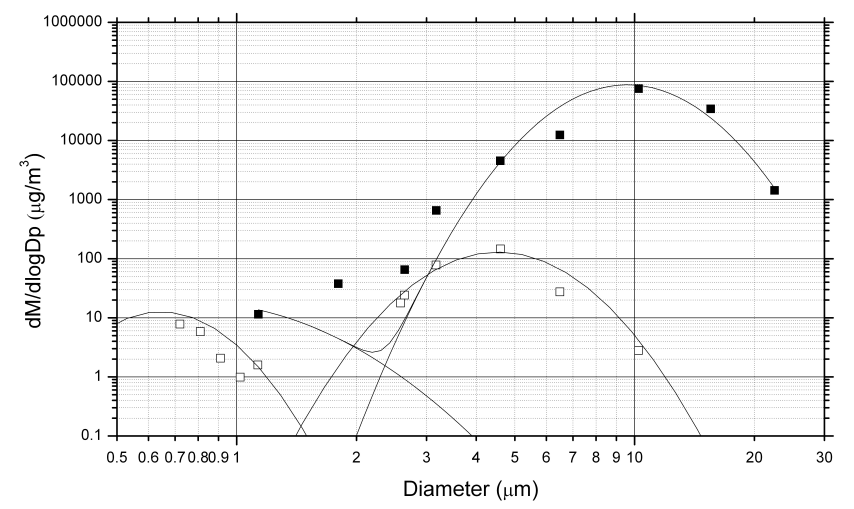

Fig. 15. Cloud generation experiments. Droplet size distribution at the maximum mass concentration during an expansion procedure (open squares) and during a saturation procedure (black Squares).

at $683 \mathrm{~nm}$, the working wavelength of the Grimm ${ }^{\circledR}$ laser diode) was plotted against the light intensity scattered by water droplets of the same diameters (complex refractive index equal to $1.33-0.0 \mathrm{i}$ ). Scattering intensity was then calculated by integrating the phase function over the collection angles of the Aerosol Spectrometer (i.e. the diffusion angle from $60^{\circ}$ to $120^{\circ}$ ). These calculations were also performed with the MiePlot v4.0 software and led to significant correction of the droplets size distribution.

The results obtained show the efficiency of both procedures. In both cases it was possible to generate a thick cloud that lasted for some minutes in the reactor in the absence of any seed aerosols which is a very unfavorable condition for droplets stabilization. In the presence of seeds, these lifetimes are of course considerably increased and eventually depend on the hygroscopic properties of the seeds. The cloud lifetime has been found systematically shorter with the expansion procedure than with the saturation. This can be easily understood as in the first case around $10 \%$ of the reacting mixture (including water) is removed from the reactor while in the second, additional water is added to the reactor. In turn, the cloud generation is faster with the first procedure as the expansion induces a fast cooling of the gas (faster than can be recorded by the Vaisala ${ }^{\circledR}$ gauge) which provokes a fast nucleation process. On the contrary, the second procedure tends to increase the temperature.

In both cases, more than $95 \%$ of the droplets follow a single distribution which is centered in the micrometer range i.e. $5 \mu \mathrm{m}$ for expansion and $10.5 \mu \mathrm{m}$ for the saturation (see Fig. 15) which fall in the order of magnitude of what can be found in cumulus cloud (Hsieh et al., 2009; Jiang et al., 2009). Furthermore, it must be noticed that the saturation experiment led to around five orders of magnitude more liquid water than the other procedure. 


\section{Conclusions}

The CESAM facility was designed to bring new insights on atmospheric multiphase photochemistry by providing new data relevant to gas phase chemistry as well as to aerosol and cloud chemistry and physics. These first results demonstrate its utility and complementarities with other chambers.

Indeed, we have shown that the realism of irradiation was excellent while its stability, the pressure control, the cleanliness of the background were also highly satisfactory. Hence, CESAM can be considered as combining most advantages of indoor and outdoor chambers. In addition, the wall properties allowed the aerosol to exhibit a lifetime long enough to study aerosol aging over several hours or days.

Chemical characterization of the chamber behavior from chemical systems relevant to smog chemistry has shown that $\mathrm{NO}_{\mathrm{x}}$ concentrations were affected by wall reactions in a manner significantly different from other chambers as reductive properties have been found. Nevertheless, this feature was efficiently described by a simple model for $\mathrm{NO}_{\mathrm{x}}$ chemistry. This additional mechanism was very efficient to reproduce most of the measured time-concentration data set for a known $\mathrm{VOC} / \mathrm{NO}_{\mathrm{x}} /$ light system showing that no major artifact was arising from wall chemistry. We believe that this will allow us to study unknown gas phase mechanisms providing that suitable control runs are performed.

Furthermore, secondary aerosol yield studies from a known chemical system has shown good reproducibility and good agreement with previous studies indicating that this chamber is also well suited for studies of secondary aerosol formation.

Preliminary study has shown that, in CESAM, one can generate in situ clouds via the adiabatic expansion of nearly saturated air with water vapor. To our best knowledge, CE$\mathrm{SAM}$ is the unique smog chamber that permits the study of photochemistry simultaneously with cloud formation and evaporation. Experimental studies which aimed at studying aqueous phase chemistry in interaction with gaseous phase are often only focused on one or two phases at a time. CESAM chamber will allow integrated experimental simulations that will permit a significantly better integration of multiphase processes in more atmospherically representative conditions.

\section{Supplementary material related to this article is available online at: http://www.atmos-meas-tech.net/4/2465/2011/ amt-4-2465-2011-supplement.pdf.}

Acknowledgements. The authors gratefully acknowledge the institutions who have provided financial support: French Ministry of research with ACI "Young Scientist" program, Ile-de-France regional Council within the SESAME program and the French National Institute for Sciences of the Universe (CNRS-INSU) within the LEFE program. This work was also supported by the EC within the I3 projects "Integrating of European Simulation Chambers for Investigating Atmospheric Processes" (EUROCHAMP, contract no. 505968 and EUROCHAMP-2, contract no. 228335).

The authors want to express their deep gratitude to Pierre Roullet (ICARE SARL, Paris) for his indefatigable involvement in the CESAM project. They also want to extend their thanks to Michel Attoui (UPEC) for the lending of short DMA and helpful discussion on nanoparticle behavior in the chamber and to Paola Formenti (LISA) for particles scattering efficiency calculations. Individuals they want to thank also include P. Zapf, N. Grand, P. Olivier and J.-M. Flaud.

Edited by: J.-L. Jimenez

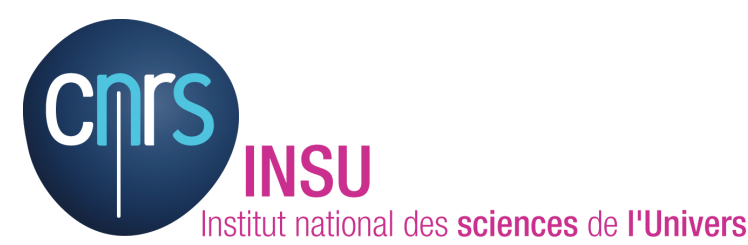

The publication of this article is financed by CNRS-INSU.

\section{References}

Afif, C., Jambert, C., Colomb, A., Eyglunent, G., Borbon, A. Daele, V., Doussin, J.-F., and Perros, P.: NitroMAC, a new instrument for HONO measurement : development and intercomparison with LOPAP, Atmos. Meas. Tech., in preparation, 2011.

Akimoto, H. and Sakamaki, F.: Correlation of the ozone formation rates with hydroxyl radical concentrations in the propylene nitrogen-oxide dry air system - effective ozone formation rate constant, Environ. Sci. Technol., 17, 94-99, 1983.

Akimoto, H., Hoshimo, M., Inoue, G., Sakamaki, F., Washida, N., and Okuda, M.: Design and characterization of the evacuable and bakable photochemical smog chamber, Environ. Sci. Technol., 13, 471-475, 1979a.

Akimoto, H., Sakamaki, F., Hoshino, M., Inoue, G., and Okuda, M.: Photochemical ozone formation in propylene-nitrogen oxide-dry air system, Environ. Sci. Technol., 13, 53-58, 1979 b.

Atkinson, R.: Atmospheric Chemistry of VOCs and $\mathrm{NO}_{\mathrm{x}}$, Atmos. Environ., 34, 2063-2101, 2000.

Atkinson, R., Baulch, D. L., Cox, R. A., Crowley, J. N., Hampson, R. F., Hynes, R. G., Jenkin, M. E., Rossi, M. J., and Troe, J.: Evaluated kinetic and photochemical data for atmospheric chemistry: Volume $\mathrm{I}-$ gas phase reactions of $\mathrm{O}_{\mathrm{x}}, \mathrm{HO}_{\mathrm{x}}, \mathrm{NO}_{\mathrm{x}}$ and $\mathrm{SO}_{\mathrm{x}}$ species, Atmos. Chem. Phys., 4, 1461-1738, doi:10.5194/acp-41461-2004, 2004.

Atkinson, R., Baulch, D. L., Cox, R. A., Crowley, J. N., Hampson, R. F., Hynes, R. G., Jenkin, M. E., Rossi, M. J., Troe, J., and IUPAC Subcommittee: Evaluated kinetic and photochemical data for atmospheric chemistry: Volume II - gas phase reactions of organic species, Atmos. Chem. Phys., 6, 3625-4055, doi:10.5194/acp-6-3625-2006, 2006.

Atkinson, R., Baulch, D. L., Cox, R. A., Crowley, J. N., Hampson, R. F., Hynes, R. G., Jenkin, M. E., Rossi, M. J., and Troe, J.: Evaluated kinetic and photochemical data for atmospheric chemistry: Volume III - gas phase reactions of inorganic halogens, 
Atmos. Chem. Phys., 7, 981-1191, doi:10.5194/acp-7-981-2007, 2007.

Baltensperger, U., Kalberer, M., Dommen, J., Paulsen, D., Alfarra, M. R., Coe, H., Fisseha, R., Gascho, A., Gysel, M., Nyeki, S., Sax, M., Steinbacher, M., Prevot, A. S. H., Sjogren, S., Weingartner, E., and Zenobi, R.: Secondary organic aerosols from anthropogenic and biogenic precursors, Faraday Discuss., 130, 265-278, 2005 .

Barnes, I. and Rudzinski, K. J.: Environmental simulation chambers: Application to atmospheric chemical processes, SpringerVerlag, New York, 2006.

Barnes, I., Becker, K. H., Carlier, P., and Mouvier, G.: FTIR study of the DMS/NO2/I2/N2 photolysis system: The reaction of IO radicals with DMS, Int. J. Chem. Kinet., 19, 489-501, 1987.

Barnes, I., Becker, K. H., Fink, E. H., Kriesche, V., Wildt, J., and Zabel, F.: Studies of atmospheric reaction systems in a temperature controlled reaction chamber using Fourier-Transformspectroscopy, First European symposium on Physico-Chemical Behaviour of Atmospheric Pollutants, Commission of the European Communities, Bruxelles, JRC - Ispra, Italy, 1979.

Barnes, I., Becker, K. H., Fink, E. H., Reimer, A., Zabel, F., and Niki, H.: FTIR spectroscopic study of the gas-phase reaction of $\mathrm{HO}_{2}$ with $\mathrm{H}_{2} \mathrm{CO}$, Chem. Phys. Lett., 115, 1-8, 1985.

Bechara, J., Borbon, A., Jambert, C., and Perros, P. E.: New off-line aircraft instrumentation for non-methane hydrocarbon measurements, Anal Bioanal. Chem., 392, 865-876, 2008.

Becker, K. H.: The European Photoreactor "EUPHORE", Final report, Contract EV5V-CT92-0059, European Community, Wuppertal, 1996.

Becker, K. H.: Overview on the development of chambers for the study of atmospheric chemical processes, in: NATO Sci. Series IV Earth Environ. Sciences, edited by: Barnes, I. and Rudzinski, K. J., Springer-Verlag, New York, 62, 1-26, 2006.

Behnke, W., Holländer, W., Koch, N. F. and Zetzsch, C.: A smog chamber for studies of the photochemical degradation of chemicals in the presence of aerosols, Atmos. Environ., 22, 1113-1120, 1988.

Bloss, C., Wagner, V., Bonzanini, A., Jenkin, M. E., Wirtz, K., Martin-Reviejo, M., and Pilling, M. J.: Evaluation of detailed aromatic mechanisms (MCMv3 and MCMv3.1) against environmental chamber data, Atmos. Chem. Phys., 5, 623-639, doi:10.5194/acp-5-623-2005, 2005.

Bower, K. N., Choularton, T. W., Gallagher, M. W., Colvile, R. N., Wells, M., Beswick, K. M., Wiedensohler, A., Hansson, H. C., Svenningsson, B., Swietlicki, E., Wendisch, M., Berner, A., Kruisz, C., Laj, P., Facchini, M. C., Fuzzi, S., Bizjak, M., Dollard, G., Jones, B., Acker, K., Wieprecht, W., Preiss, M., Sutton, M. A., Hargreaves, K. J., StoretonWest, R. L., Cape, J. N., and Arends, B. G.: Observations and modeling of the processing of aerosol by a hill cap cloud, Atmos. Environ., 31, 2527-2543, 1997.

Brauers, T., Bohn, B., Johnen, F.-J., Rohrer, R., Rodriguez Bares, S., Tillmann, R., and Wahner, A.: The atmosphere simulation chamber SAPHIR: a tool for the investigation of photochemistry, EGS - AGU - EUG Joint Assembly, Nice, France, 2003.

Bunz, H., Möhler, O., Naumann, K. H., Saathoff, H., Schöck, W., and Schurath, U.: Novel Aerosol Chamber Facility AIDA: Status and First Results, The EU Air Pollution Symposium'96, Venice, Italy, 1996.
Calvert, J. G. and Pitts, J. N. J.: Photochemistry, John Wiley and Sons, Inc., New-York, 1966.

Camredon, M., Aumont, B., Lee-Taylor, J., and Madronich, S.: The SOA/VOC/NO $\mathrm{NO}_{\mathrm{x}}$ system: an explicit model of secondary organic aerosol formation, Atmos. Chem. Phys., 7, 5599-5610, doi:10.5194/acp-7-5599-2007, 2007.

Carter, W. P. L.: Environmental chamber studies of atmospheric reactivities of Volatile Organic Compounds: effect of varying chamber and light source Contract A032-0692, California Air Resources Board, 1995.

Carter, W. P. L.: Evaluation of atmospheric impacts of selected coatings VOC emissions, Progress Report to the California Air Resources Board Contract No. 00-333, 2003.

Carter, W. P. L.: Documentation of the SAPRC-99 chemical mechanism for VOC reactivity assessment. Final Report to California Air Resources Board, Contract 92-329 and 95-308, Riverside, 2000.

Carter, W. P. L.: The UCR EPA environmental chamber, NATO Advances Research Workshop on Environmental Simulation Chambers: Application to Atmospheric Chemical Processes, 1-4 October 2004, Zakopane, Poland, Springer, 2006.

Carter, W. P. L. and Lurmann, F. W.: Evaluation of a detailed gas-phase atmospheric reaction mechanism using environmental chamber data, Atmos. Environ., 25, 2771-2806, 1991.

Carter, W. P. L., Lloyd, A. C., Sprung, J. L., and Pitts Jr., J. N.: Computer modeling of smog chamber data: Progress in validation of a detailed mechanism for the photooxidation of propene and n-butane in photochemical smog, Int. J. Chem. Kinet., 11, 45-101, 1979.

Carter, W. P. L., Cocker III, D. R., Fitz, D. R., Malkina, I. L., Bumiller, K., Sauer, C. G., Pisano, J. T., Bufalino, C., and Song, C.: A new environmental chamber for evaluation of gas-phase chemical mechanisms and secondary aerosol formation, Atmos. Environ., 39, 7768-7788, 2005.

Chan, M. N., Chan, A. W. H., Chhabra, P. S., Surratt, J. D., and Seinfeld, J. H.: Modeling of secondary organic aerosol yields from laboratory chamber data, Atmos. Chem. Phys., 9, 56695680, doi:10.5194/acp-9-5669-2009, 2009.

Chiappini, L., Perraudin, E., Durand-Jolibois, R., and Doussin, J. F.: Development of a supercritical fluid extraction-gas chromatography-mass spectrometry method for the identification of highly polar compounds in secondary organic aerosols formed from biogenic hydrocarbons in smog chamber experiments, Anal Bioanal. Chem., 386, 1749-1759, 2006.

Choularton, T. W., Bower, K. N., Beswick, K. M., Parkin, M., and Kaye, A.: A study of the effects of cloud processing of aerosol on the microphysics of cloud, Q. J. Roy. Meteorol. Soc., 124, 1377-1389, 1998.

Cocker III, D. R., Flagan, R. C., and Seinfeld, J. H.: State of the art chamber facility for studying atmospheric aerosol chemistry, Environ. Sci. Technol., 35, 2594-2601, 2001a.

Cocker III, D. R., Clegg, S. L., Flagan, R. C., and Seinfeld, J. H.: The effect of water on gas-particle partitioning of secondary organic aerosol, Part I: $\alpha$-pinene/ozone system, Atmos. Environ., 35, 6049-6072, $2001 \mathrm{~b}$.

Cocker III, D. R., Mader, B. T., Kalberer, M., Flagan, R. C., and Seinfeld, J. H.: The effect of water on gas-particle partitioning of secondary organic aerosol: II. m-xylene and 1,3,5trimethylbenzene photooxidation systems, Atmos. Environ., 35, 
6073-6085, 2001c.

Crumeyrolle, S., Gomes, L., Tulet, P., Matsuki, A., Schwarzenboeck, A., and Crahan, K.: Increase of the aerosol hygroscopicity by cloud processing in a mesoscale convective system: a case study from the AMMA campaign, Atmos. Chem. Phys., 8, 6907-6924, doi:10.5194/acp-8-6907-2008, 2008.

Crump, J. G. and Seinfeld, J. H.: Turbulent deposition and gravitational sedimentation of an aerosol in a vessel of arbitrary shape, J. Aerosol Sci., 12, 405-415, 1981.

Crump, J. G., Flagan, R. C., and Seinfeld, J. H.: Particle Wall Loss Rates in Vessels, Aeros. Sci. Tech., 2, 303-309, 1983.

Curtis, A. R.: The FACSIMILE numerical integrator for stiff initial value problems AERE - Report no. 9352, Computer science and systems division, AERE Harwell, Oxfordshire, 1979.

De Juan, A. and Tauler, R.: Chemometrics applied to unravel multicomponent processes and mixtures: Revisiting latest trends in multivariate resolution, Anal. Chim. Acta, 500, 195-210, 2003.

De Haan, D. O., Brauers, T., Oum, K., Stutz, J., Nordmeyer, T., and Finlayson-Pitts, B. J.: Heterogeneous chemistry in the troposphere: experimental approaches and applications to the chemistry of sea salt particles, Int. Rev. Phys. Chem., 18, 343-385, 1999.

De Haan, D. O., Corrigan, A. L., Smith, K. W., Stroik, D. R., Turley, J. J., Lee, F. E., Tolbert, M. A., Jimenez, J. L., Cordova, K. E., and Ferrell, G. R.: Secondary Organic Aerosol-Forming Reactions of Glyoxal with Amino Acids, Environ. Sci. Technol., 43, 2818-2824, 2009.

De More,W., Sander, S. P., Golden, D. M., Hampson, R. F., Kurylo, M. J., Howard, C., Ravishankara, A. R., Kolb, A. R., and Molina, M. J.: Chemical kinetics and photochemical data for use in stratospheric modeling, JPL Publ. No. 94-26, Jet Propulsion Laboratory, Pasadena, CA, 1994.

Dodge, M. C.: Chemical oxidant mechanisms for air quality modeling: critical review, Atmos. Environ., 34, 2103-2130, 2000.

Donahue, N. M., Hartz, K. E. H., Chuong, B., Presto, A. A., Stanier, C. O., Rosenhorn, T., Robinson, A. L., and Pandis, S. N.: Critical factors determining the variation in SOA yields from terpene ozonolysis: A combined experimental and computational study, Faraday Discuss., 130, 295-309, 2005.

Doussin, J. F., Ritz, D., Durand-Jolibois, R., Monod, A., and Carlier, P.: Design of an environmental chamber for the study of atmospheric chemistry: New developments in the analytical device, Analusis, 25, 236-242, 1997.

Doyle, G. J.: Design of a facility (smog chamber) for studying photochemical reactions under simulated tropospheric conditions, Environ. Sci. Technol., 4, 907-916, 1970.

Dunlea, E. J., Herndon, S. C., Nelson, D. D., Volkamer, R. M., San Martini, F., Sheehy, P. M., Zahniser, M. S., Shorter, J. H., Wormhoudt, J. C., Lamb, B. K., Allwine, E. J., Gaffney, J. S., Marley, N. A., Grutter, M., Marquez, C., Blanco, S., Cardenas, B., Retama, A., Ramos Villegas, C. R., Kolb, C. E., Molina, L. T., and Molina, M. J.: Evaluation of nitrogen dioxide chemiluminescence monitors in a polluted urban environment, Atmos. Chem. Phys., 7, 2691-2704, doi:10.5194/acp-7-2691-2007, 2007.

Ervens, B., Carlton, A. G., Turpin, B. J., Altieri, K. E., Kreidenweis, S. M., and Feingold, G.: Secondary organic aerosol yields from cloud-processing of isoprene oxidation products, Geophys. Res. Lett., 35, L02816, doi:10.1029/2007GL031828, 2008.

Ferrari, C. P., Durand-Jolibois, R., Carlier, P., Jacob, V., Roche, A.,
Foster, P., and Fresnet, P.: Comparison between two carbonyl measurement methods in the atmosphere, Analusis, 27, 45-53, 1999.

Field, P. R., Möhler, O., Connolly, P., Krämer, M., Cotton, R., Heymsfield, A. J., Saathoff, H., and Schnaiter, M.: Some ice nucleation characteristics of Asian and Saharan desert dust, Atmos. Chem. Phys., 6, 2991-3006, doi:10.5194/acp-6-2991-2006, 2006.

Finlayson-Pitts, B. J. and Pitts Jr., J. N.: Atmospheric chemistry: Fundamentals and experimental techniques, John Wiley and Sons, New-York, 1986.

Finlayson-Pitts, B. J. and Pitts Jr., J. N.: The chemistry of the Lower and Upper Atmosphere: Theory, experiments and applications, Academic Press, New-York, 2000.

Finlayson-Pitts, B. J., Wingen, L. M., Sumner, A. L., Syomin, D., and Ramazan, K. A.: The heterogeneous hydrolysis of $\mathrm{NO}_{2}$ in laboratory systems and in outdoor and indoor atmospheres: An integrated mechanism, Phys. Chem. Chem. Phys., 5, 223-242, 2003.

Glowacki, D. R., Goddard, A., Hemavibool, K., Malkin, T. L., Commane, R., Anderson, F., Bloss, W. J., Heard, D. E., Ingham, T., Pilling, M. J., and Seakins, P. W.: Design of and initial results from a Highly Instrumented Reactor for Atmospheric Chemistry (HIRAC), Atmos. Chem. Phys., 7, 5371-5390, doi:10.5194/acp7-5371-2007, 2007.

Griffin, R. J., Cocker, D. R., Flagan, D. R., and Seinfeld, J. H.: Organic aerosol formation from the oxidation of biogenic hydrocarbons, J. Geophys. Res.-Atmos., 104, 3555-3567, 1999.

Griffiths, P. R. and De Haseth, J. A.: Fourier transform infrared spectrometry, Wiley-Interscience, New-York, 1986.

Grosjean, D.: Wall loss of gaseous pollutants in outdoor Teflon chambers, Environ. Sci. Technol., 19, 1059-1065, 1985.

Hagen, D. E., Schmitt, J., Trueblood, M., Carstens, J., White, D. R., and Alofs, D. J.: Condensation Coefficient Measurement for Water in the UMR Cloud Simulation Chamber, J. Atmos. Sci., 46, 803-816, 1989.

Hallquist, M., Wenger, J. C., Baltensperger, U., Rudich, Y., Simpson, D., Claeys, M., Dommen, J., Donahue, N. M., George, C., Goldstein, A. H., Hamilton, J. F., Herrmann, H., Hoffmann, T., Iinuma, Y., Jang, M., Jenkin, M. E., Jimenez, J. L., Kiendler-Scharr, A., Maenhaut, W., McFiggans, G., Mentel, Th. F., Monod, A., Prévôt, A. S. H., Seinfeld, J. H., Surratt, J. D., Szmigielski, R., and Wildt, J.: The formation, properties and impact of secondary organic aerosol: current and emerging issues, Atmos. Chem. Phys., 9, 5155-5236, doi:10.5194/acp-95155-2009, 2009

Hatakeyama, S., Akimoto, H., and Washida, N.: Effect of temperature on the formation of photochemical ozone in a propene/ $\mathrm{NO}_{\mathrm{x}} /$ Air irradiation system, Environ. Sci. Technol., 25 , 1884-1890, 1991.

Hatzianastassiou, N., Wobrock, W., and Flossmann, A. I.: The effect of cloud-processing of aerosol particles on clouds and radiation, Tellus B, 50, 478-490, 1998.

Hegg, D. A., Covert, D. S., Jonsson, H., Khelif, D., and Friehe, C. A.: Observations of the impact of cloud processing on aerosol light-scattering efficiency, Tellus B, 56, 285-293, 2004.

Hellpointner, E. and Gaab, S.: Detection of methyl, hydroxymethyl and hydroxyethyl hydroperoxides in air and precipitation, Nature, 337, 631-634, 1989. 
Hjorth, J., Ottobrini, G., Cappelanni, F., and Restelli, G.: A Fourier transform infrared study of the rate constant of the homogeneous gas-phase reaction $\mathrm{N}_{2} \mathrm{O}_{5}+\mathrm{H}_{2} \mathrm{O}$ and determination of absolute infrared band intensities of $\mathrm{N}_{2} \mathrm{O}_{5}$ and $\mathrm{HNO}_{3}$, J. Phys. Chem., 91, 1565-1568, 1987.

Hobbs, P. V.: The 11th International-Conference on Clouds and Precipitation, B. Am. Meteorol. Soc., 74, 835-844, 1993.

Hoffmann, T., Odum, J., Bowman, F., Collins, D., Klockow, D., Flagan, R. C., and Seinfeld, J. H.: Formation of organic aerosols from the oxidation of biogenic hydrocarbons, J. Atmos. Chem., 26, 189-222, 1997.

Hoppel, W. A., Frick, G. M., Fitzgerald, J. W., and Wattle, B. J.: A cloud chamber study of the effect that non precipitating water clouds have on the aerosol-size distribution, Aerosol Sci. Tech., 20, 1-30, 1994.

Horie, O. and Moortgat, G. K.: Reaction of $\mathrm{CH} 3 \mathrm{C}(\mathrm{O}) \mathrm{O}_{2}$ radicals with $\mathrm{CH}_{3} \mathrm{O}_{2}$ and $\mathrm{HO}_{2}$ between 263 and $333 \mathrm{~K}$ - a product study, J. Chem. Soc. - Faraday Trans., 88, 3305-3312, 1992.

Hsieh, W. C., Nenes, A., Flagan, R. C., Seinfeld, J. H., Buzorius, G., and Jonsson, H.: Parameterization of cloud droplet size distributions: Comparison with parcel models and observations, J. Geophys. Res.-Atmos., 114, D11205, doi:10.1029/2008JD011387, 2009.

Hynes, R. G., Angove, D. E., Saunders, S. M., Haverd, V., and Azzi, M.: Evaluation of two MCM v3.1 alkene mechanisms using indoor environmental chamber data, Atmos. Environ., 39, 72517262, 2005.

IPCC: Climate Change, The Physical Science Basis, in: Intergovernmental Panel on Climate Change, edited by: Solomon, S., Qin, D., Manning, M., Marquis, M., Averyt, K., Tignor, M. M. B., Miller Jr., H. L., and Chen, Z., Cambridge University Press, Cambridge, UK, 2007.

Jaoui, M., Sexton, K. G., and Kamens, R. M.: Reaction of $\alpha$ cedrene with ozone: mechanism, gas and particulate products distribution, Atmos. Environ., 38, 2709-2725, 2004.

Jeffries, H., Fox, D., and Kamens, R.: Outdoor smog chamber studies: light effects relative to indoor chambers, Environ. Sci. Technol., 10, 1006-1011, 1976.

Jenkin, M. E., Hurley, M. D., and Wallington, T. J.: Investigation of the radical product channel of the $\mathrm{CH}_{3} \mathrm{C}(\mathrm{O}) \mathrm{O}_{2}+\mathrm{HO}_{2}$ reaction in the gas phase, Phys. Chem. Chem. Phys., 3149-3162, 2007.

Jiang, H. L., Feingold, G., and Koren, I.: Effect of aerosol on trade cumulus cloud morphology, J. Geophys. Res.-Atmos., 114, D11209, doi:10.1029/2009JD011750, 2009.

Kalberer, M., Sax, M., and Samburova, V.: Molecular size evolution of oligomers in organic aerosols collected in urban atmospheres and generated in a smog chamber, Environ. Sci. Technol., 40, 5917-5922, 2006.

Kanakidou, M., Seinfeld, J. H., Pandis, S. N., Barnes, I., Dentener, F. J., Facchini, M. C., Van Dingenen, R., Ervens, B., Nenes, A., Nielsen, C. J., Swietlicki, E., Putaud, J. P., Balkanski, Y., Fuzzi, S., Horth, J., Moortgat, G. K., Winterhalter, R., Myhre, C. E. L., Tsigaridis, K., Vignati, E., Stephanou, E. G., and Wilson, J.: Organic aerosol and global climate modelling: a review, Atmos. Chem. Phys., 5, 1053-1123, doi:10.5194/acp-5-1053-2005, 2005.

Karl, M., Brauers, T., Dorn, H.-P., Holland, F., Komenda, M., Poppe, D., Rohrer, F., Rupp, L., Schaub, A., and Wahner, A.: Kinetic Study of the $\mathrm{OH}$-isoprene and $\mathrm{O}_{3}$-isoprene reaction in the atmosphere simulation chamber, SAPHIR, Geophys. Res. Lett., 31, L05117, doi:10.1029/2003GL019189, 2004.

King, S. M., Rosenoern, T., Shilling, J. E., Chen, Q., Wang, Z., Biskos, G., McKinney, K. A., Pöschl, U., and Martin, S. T.: Cloud droplet activation of mixed organic-sulfate particles produced by the photooxidation of isoprene, Atmos. Chem. Phys., 10, 3953-3964, doi:10.5194/acp-10-3953-2010, 2010.

Laven, P.: Simulation of rainbows, coronas, and glories by use of Mie theory, Appl. Optics, 42, 436-444, 2003.

Leone, J. A., Flagan, R. C., Grosjean, D., and Seinfeld, J. H.: An outdoor smog chamber and modeling study of toluene $\mathrm{NO}_{\mathrm{x}}$ photooxidation, Int. J. Chem. Kinet., 17, 177-216, 1985.

Lim, Y. B. and Ziemann, P. J.: Products and mechanism of secondary organic aerosol formation from reactions of n-alkanes with $\mathrm{OH}$ radicals in the presence of $\mathrm{NO}_{\mathrm{x}}$, Environ. Sci. Technol., 39, 9229-9236, 2005.

Linke, C., Möhler, O., Veres, A., Mohácsi, Á., Bozóki, Z., Szabó, G., and Schnaiter, M.: Optical properties and mineralogical composition of different Saharan mineral dust samples: a laboratory study, Atmos. Chem. Phys., 6, 3315-3323, doi:10.5194/acp-63315-2006, 2006.

Liu, X., Jeffries, H. E., and Sexton, K. G.: Atmospheric photochemical degradation of 1,4-unsaturated dicarbonyls, Environ. Sci. Technol., 33, 4212-4220, 1999.

Loza, C. L., Chan, A. W. H., Galloway, M. M., Keutsch, F. N., Flagan, R. C., and Seinfeld, J. H.: Characterization of Vapor Wall Loss in Laboratory Chambers, Environ. Sci. Technol., 44, 50745078, 2010.

Madronich, S.: Photodissociation in the Atmosphere, 1. Actinic flux and the effects of ground reflections and clouds, J. Geophys. Res.-Atmos., 92, 9740-9752, 1987.

Madronich, S. and Flocke, S.: The role of solar radiation in atmospheric chemistry, in: Handbook of Environmental Chemistry, edited by: Boule, P., Springer-Verlag, Heidelberg, 1-26, 1999.

Marenco, A., Gouget, H., Nédélec, P., Pagès, J. P., and Karcher, F.: Evidence of a long-term increase in tropospheric ozone from Pic du Midi data series: consequences: positive radiative forcing, J. Geophys. Res., 99, 16617-16632, 1994.

Martin-Reviejo, M. and Wirtz, K.: Is Benzene a Precursor for Secondary Organic Aerosol?, Environ. Sci. Technol., 39, 10451054, 2005.

Maso, M., Mentel, T., Kiendler-Scharr, A., Hohaus, T., Kleist, E., Miebach, M., Tillmann, R., Uerlings, R., Fisseha, R., Griffiths, P., Rudich, Y., Dinar, E., and Wildt, J.: Aerosol Formation from Plant Emissions: The Julich Plant Chamber Experiments Nucleation and Atmospheric Aerosols, edited by: O'Dowd, C. D. and Wagner, P. E., Springer, Netherlands, 924-927, 2007.

Matsunaga, A. and Ziemann, P. J.: Gas-Wall Partitioning of Organic Compounds in a Teflon Film Chamber and Potential Effects on Reaction Product and Aerosol Yield Measurements, Aerosol Sci. Tech., 44, 881-892, 2010.

McMurry, P. H. and Grosjean, D.: Gas and aerosol wall losses in Teflon film smog chambers, Environ. Sci. Technol., 19, 11761182, 1985.

McMurry, P. H. and Rader, D. J.: Aerosol Wall Losses in Electrically Charged Chambers, Aerosol Sci. Tech., 4, 249-268, 1985.

Mentel, T., Bleilebens, D., and Wahner, A.,: A study of nighttime nitrogen oxide oxidation in a large reaction chamber - The fate of $\mathrm{NO}_{2}, \mathrm{~N}_{2} \mathrm{O}_{5}, \mathrm{HNO}_{3}$ and $\mathrm{O}_{3}$ at different humidities, Atmos. 
Environ., 30, 4007-4020, 1996.

Metzger, A., Dommen, J., Gaeggeler, K., Duplissy, J., Prevot, A. S. H., Kleffmann, J., Elshorbany, Y., Wisthaler, A., and Baltensperger, U.: Evaluation of 1,3,5 trimethylbenzene degradation in the detailed tropospheric chemistry mechanism, MCMv3.1, using environmental chamber data, Atmos. Chem. Phys., 8, 6453-6468, doi:10.5194/acp-8-6453-2008, 2008.

Meyer, N. K., Duplissy, J., Gysel, M., Metzger, A., Dommen, J., Weingartner, E., Alfarra, M. R., Prevot, A. S. H., Fletcher, C., Good, N., McFiggans, G., Jonsson, Å. M., Hallquist, M., Baltensperger, U., and Ristovski, Z. D.: Analysis of the hygroscopic and volatile properties of ammonium sulphate seeded and unseeded SOA particles, Atmos. Chem. Phys., 9, 721-732, doi:10.5194/acp-9-721-2009, 2009.

Mirme, A., Tamm, A., Mordas, G., Vana, M., Uin, J., Mirme, S., Bernotas, T., Laakso, L., Hirsikko, A., and Kulmala, M.: A wide range multi-channel Air Ion Spectrometer, Boreal Environ. Res., 12, 247-264, 2007.

Molina, L. T. and Molina, M. J.: Absolute absorption cross-sections of ozone in the $185 \mathrm{~nm}$ to $350 \mathrm{~nm}$ wavelength range, J. Geophys. Res.-Atmos., 91, 14501-14508, 1986.

Obrien, R. J.: Photostationary State in Photochemical Smog Studies, Environ. Sci. Technol., 8, 579-583, 1974.

Odum, J. R., Hoffmann, T., Bowman, F., Collins, D., Flagan, R. C., and Seinfeld, J. H.: Gas/Particle partitioning and secondary organic aerosol yields, Environ. Sci. Technol., 30, 2580-2585, 1996.

Pankow, J. F.: An absorption model of the gas/aerosol partitioning involved in the formation of secondary organic aerosol, Atmos. Environ., 28, 189-193, 1994.

Pathak, R. K., Presto, A. A., Lane, T. E., Stanier, C. O., Donahue, N. M., and Pandis, S. N.: Ozonolysis of $\alpha$-pinene: parameterization of secondary organic aerosol mass fraction, Atmos. Chem. Phys., 7, 3811-3821, doi:10.5194/acp-7-3811-2007, 2007.

Paulsen, D., Dommen, J., Kalberer, M., Prévot, A., Richter, R., Sax, M., Steinbacher, M., Weingartner, E., and Baltensperger, U.: Secondary Organic Aerosol formation by irradiation of 1,3,5Trimethylbenzene/ $/ \mathrm{NO}_{\mathrm{x}} / \mathrm{H}_{2} \mathrm{O}$ in a new reaction chamber for atmospheric chemistry and physics, Environ. Sci. Technol., 39, 2668-2678, 2005.

Pinceloup, S., Laverdet, G., Maguin, F., Doussin, J. F., Carlier, P., and Le Bras, G.: Laboratory investigation of the photooxidation of formaldehyde combining FTIR analysis of stable species and $\mathrm{HO}_{2}$ detection by the chemical amplifier technique, J. Photochem. Photobiol. A-Chem., 157, 275-281, 2003.

Pruppacher, H. R. and Klett, J. D.: Microphysics of Clouds and Precipitation, Kluwer Academic Publishers, London, 954, 1997.

Pun, B. K., Wu, S. Y., Seigneur, C., Seinfeld, J. H., Griffin, R. J., and Pandis, S.: Uncertainties in modelling secondary organic aerosols: three-dimensional modeling studies in Nashville/Western Tennessee, Environ. Sci. Technol., 37, 36473661, 2003.

Ródenas, M., Soria, E., Martín, J. D., Picquet-Varrault, B., and Doussin, J.-F.: Development of Methodologies for IR Analysis at the EUPHORE Simulation Chambers: A Case Study, Atmospheric Chemical Mechanisms, The ARC, University of California Davis, 10-12 December 2008, 2010.

Saathoff, H., Naumann, K.-H., Möhler, O., Jonsson, Å. M., Hallquist, M., Kiendler-Scharr, A., Mentel, Th. F., Tillmann, R., and
Schurath, U.: Temperature dependence of yields of secondary organic aerosols from the ozonolysis of $\alpha$-pinene and limonene, Atmos. Chem. Phys., 9, 1551-1577, doi:10.5194/acp-9-15512009, 2009.

Saunders, S. M., Pascoe, S., Johnson, A. P., Pilling, M. J., and Jenkin, M. E.: Development and preliminary test results of an expert system for the automatic generation of tropospheric VOC degradation mechanisms, Atmos. Environ., 37, 1723-1735, 2003.

Seakins, P. W.: A brief review of the use of environmental chambers for gas phase studies of kinetics, chemical mechanisms and characterisation of field instruments, Eur. Phys. J., 9, 143-163, 2010.

Seinfeld, J. H., Kleindienst, T. E., Edney, E. O., and Cohen, J. B.: Aerosol growth in a steady-state, continuous flow chamber: Application to studies of secondary aerosol formation, Aerosol Sci. Tech., 37, 728-734, 2003.

Seinfeld, J. H. and Pandis, S.: Air Pollution to Climate, John Wiley and Sons, 1997

Seinfeld, J. H. and Pankow, J. F.: Organic atmospheric particulate material, Ann. Rev. Phys. Chem., 54, 121-140, 2003.

Simon, A., Gast, J., and Keens, A.: Fourier spectrometer, Patent no. 5309217, Bruker, Analytische Messtechnik,USA, 1994.

Steele, R. L., Davis, C. I., and Procter, W.: Design and development of ground type silver iodide generators, B. Am. Meteorol. Soc., $51,105,1970$.

Stratmann, F., Kiselev, A., Wurzler, S., Wendisch, M., Heintzenberg, J., Charlson, R. J., Diehl, K., Wex, H., and Schmidt, S.: Laboratory studies and numerical simulations of cloud droplet formation under realistic supersaturation conditions, J. Atmos. Ocean. Tech., 21, 876-887, 2004.

Su, F., Calvert, J. G., Shaw, J. H., Niki, H., Maker, P. D., Savage, P. M., and Breitenbach, L. D.: Spectroscopic and kinetic studies of a new metastable species in the photooxidation of the gaseous formaldehyde, Chem. Phys. Lett., 65, 221-224, 1979.

Takekawa, H., Minoura, H., and Yamazaki, S.: Temperature dependence of secondary organic aerosol formation by photo-oxidation of hydrocarbons, Atmos. Environ., 37, 3413-3424, 2003.

Thuener, L. P.,Bardini, P., Rea, G. C., and Wenger, J. C.: Kinetics of the Gas-Phase Reactions of $\mathrm{OH}$ and $\mathrm{NO}_{3}$ Radicals with Dimethylphenols, J. Phys. Chem. A, 108, 11019-11025, 2004.

Thuner, L. P., Bardini, P., Rea, G. J., and Wenger, J. C.: Kinetics of the gas-phase reactions of $\mathrm{OH}$ and $\mathrm{NO}_{3}$ radicals with dimethylphenols, J. Phys. Chem. A, 108, 11019-11025, 2004.

Veyret, B., Lesclaux, R., Rayez, M. T., Rayez, J. C., Cox, R. A., and Moortgat, G. K.: Kinetics and mechanism of the photo-oxidation of formaldehyde, J. Phys. Chem. A, 93, 2368-2382, 1989.

Voigt, S., Orphal, J., Bogumil, K., and Burrows, J. P.: The temperature dependence $(203-293 \mathrm{~K})$ of the absorption cross sections of $\mathrm{O}_{3}$ in the $230-850 \mathrm{~nm}$ region measured by Fourier-transform spectroscopy, J. Photochem. Photobiol. A, 143, 1-9, 2001.

Wagner, R., Bunz, H., Linke, C., Mohler, O., Naumann, K. H., Saathoff, H., Schnaiter, M., and Schurath, U.: Chamber simulations of cloud chemistry: The AIDA chamber, Environmental Simul. Chamb., 62, 67-82, 2006.

White, J. U.: Long optical path of large aperture, J. Opt. Soc. Am., 32, 285-288, 1942.

Williams, J., de Reus, M., Krejci, R., Fischer, H., and Ström, J.: Application of the variability-size relationship to atmospheric 
aerosol studies: estimating aerosol lifetimes and ages, Atmos. Chem. Phys., 2, 133-145, doi:10.5194/acp-2-133-2002, 2002.

Winer, A. M., Breuer, G. M., Carter, W. P. L., Darnall, K. R., and Pitts, J. N.: Effect of ultraviolet spectral distribution on the photochemistry of simulated polluted atmospheres, Atmos. Environ., 13, 989-998, 1979.

Winer, A. M., Graham, R. A., Doyle, J. G., Bekowies, P. J., Mac Affee, J. M., and Pitts, J. N.: An evacuable environmental chamber and solar simulator facility for the study of atmospheric photochemistry, Adv. Environ. Sci. Technol., 10, 461-511, 1980.
Wirtz, K. and Martin-Reviejo, M.: Density of secondary organic aerosols, J. Aerosol Sci., 34, S223-S224, 2003.

Wu, S., Lu, Z., Hao, J., Zhao, Z., Li, J., Takekawa, H., Minoura, H., and Yasuda, A.: Construction and characterization of an atmospheric simulation smog chamber, Science Press, co-published with Springer-Verlag GmbH, Adv. Atmos. Sci., 24, 250-258, 2006.

Zhang, J. Y., Hartz, K. E. H., Pandis, S. N., and Donahue, N. M.: Secondary organic aerosol formation from limonene ozonolysis: Homogeneous and heterogeneous influences as a function of $\mathrm{NO}_{\mathrm{x}}$, J. Phys. Chem. A, 110, 11053-11063, 2006. 